\title{
Macroevolutionary patterns in the evolutionary radiation of archosaurs (Tetrapoda: Diapsida)
}

\author{
Stephen L. Brusatte ${ }^{1,2}$, Michael J. Benton ${ }^{3}$, Graeme T. Lloyd ${ }^{4}$, \\ Marcello Ruta ${ }^{3}$ and Steve C. Wang ${ }^{5}$
}

\author{
${ }^{1}$ Division of Paleontology, American Museum of Natural History, Central Park West at 79th Street, New York, \\ NY 10024, USA \\ Email: sbrusatte@amnh.org \\ ${ }^{2}$ Department of Earth and Environmental Sciences, Columbia University, New York, NY, USA \\ ${ }^{3}$ School of Earth Sciences, University of Bristol, Wills Memorial Building, Queens Road, Bristol, BS8 1RJ, UK \\ ${ }^{4}$ Department of Palaeontology, Natural History Museum, Cromwell Road, London SW7 5BD, UK \\ ${ }^{5}$ Department of Mathematics and Statistics, Swarthmore College, Swarthmore, PA 19081, USA
}

\begin{abstract}
The rise of archosaurs during the Triassic and Early Jurassic has been treated as a classic example of an evolutionary radiation in the fossil record. This paper reviews published studies and provides new data on archosaur lineage origination, diversity and lineage evolution, morphological disparity, rates of morphological character change, and faunal abundance during the Triassic-Early Jurassic. The fundamental archosaur lineages originated early in the Triassic, in concert with the highest rates of character change. Disparity and diversity peaked later, during the Norian, but the most significant increase in disparity occurred before maximum diversity. Archosaurs were rare components of Early-Middle Triassic faunas, but were more abundant in the Late Triassic and pre-eminent globally by the Early Jurassic. The archosaur radiation was a drawn-out event and major components such as diversity and abundance were discordant from each other. Crurotarsans (crocodile-line archosaurs) were more disparate, diverse, and abundant than avemetatarsalians (bird-line archosaurs, including dinosaurs) during the Late Triassic, but these roles were reversed in the Early Jurassic. There is no strong evidence that dinosaurs outcompeted or gradually eclipsed crurotarsans during the Late Triassic. Instead, crurotarsan diversity decreased precipitously by the end-Triassic extinction, which helped usher in the age of dinosaurian dominance.
\end{abstract}

KEY WORDS: Archosauria, Crocodylomorpha, dinosaurs, disparity, diversity, evolution, extinction, Jurassic, macroevolution, Mesozoic, rauisuchians, Triassic

Birds and crocodiles are two of the most distinctive and successful groups of extant terrestrial vertebrates. Despite their many dissimilarities in outward appearance, birds and crocodiles are sister taxa among living vertebrates and together comprise the clade Archosauria (Fig. 1; Cope 1869; Romer 1956; Sereno 1991; Benton 2005). The archosaur crown clade is an ancient group, which originated approximately 250 million years ago and also encompasses an array of extinct taxa restricted to the Mesozoic. These include non-avian dinosaurs, the ancestors of birds, as well as several clades of close crocodilian relatives that lived only during the Triassic (phytosaurs, aetosaurs, ornithosuchids, 'rauisuchians') (Fig. 1; Gauthier 1986; Benton \& Clark 1988; Benton 1999, 2004; Irmis et al. 2007; Brusatte et al. 2010a). Since its origin in the Late Permian or Early Triassic, the archosaur clade has been a successful and often dominant group, and has filled a variety of ecological roles in terrestrial ecosystems worldwide.

Successful groups such as archosaurs, broadly distributed and comprising numerous species of diverse morphology and ecological habits, must necessarily begin with a single ancestral lineage at a certain time and place. Over the course of millions of years during the Triassic and Early Jurassic, the archosaur lineage expanded into an extraordinarily broad array of morphological and ecological forms. This macroevolutionary event, the evolutionary radiation of archosaurs, has long been of interest to researchers (e.g. Romer 1956; Bakker 1971; Sill 1974; Charig 1980, 1984; Benton 1983, 1988, 2004; Nesbitt 2003). In fact, the earliest phase of archosaur history has often been treated as a classic example of an evolutionary radiation in the fossil record (e.g., Benton 1983, 2009; Brusatte et al. 2008a, b, 2010b; Langer et al. 2010). Therefore, understanding the patterns and tempo of the first 50 million years of archosaur history is central not only to specialist debates about archosaur evolution, but also to more general questions about large-scale evolutionary patterns and processes on long time scales.

Although perpetually the subject of debate and speculation, many details of the archosaur radiation have remained mysterious. This is largely due to a poor Early-Middle Triassic fossil record, a paucity of comprehensive phylogenetic analyses and anatomical descriptions for key taxa, and an emphasis on a literal reading of the fossil record rather than more objective macroevolutionary and statistical analyses. Fortunately, several key developments over the past decade now allow researchers to examine the evolutionary radiation of archosaurs in unprecedented detail. Important new fossils have been discovered across the globe, including specimens from previously undersampled intervals (Gower 1999; Nesbitt 2003; 


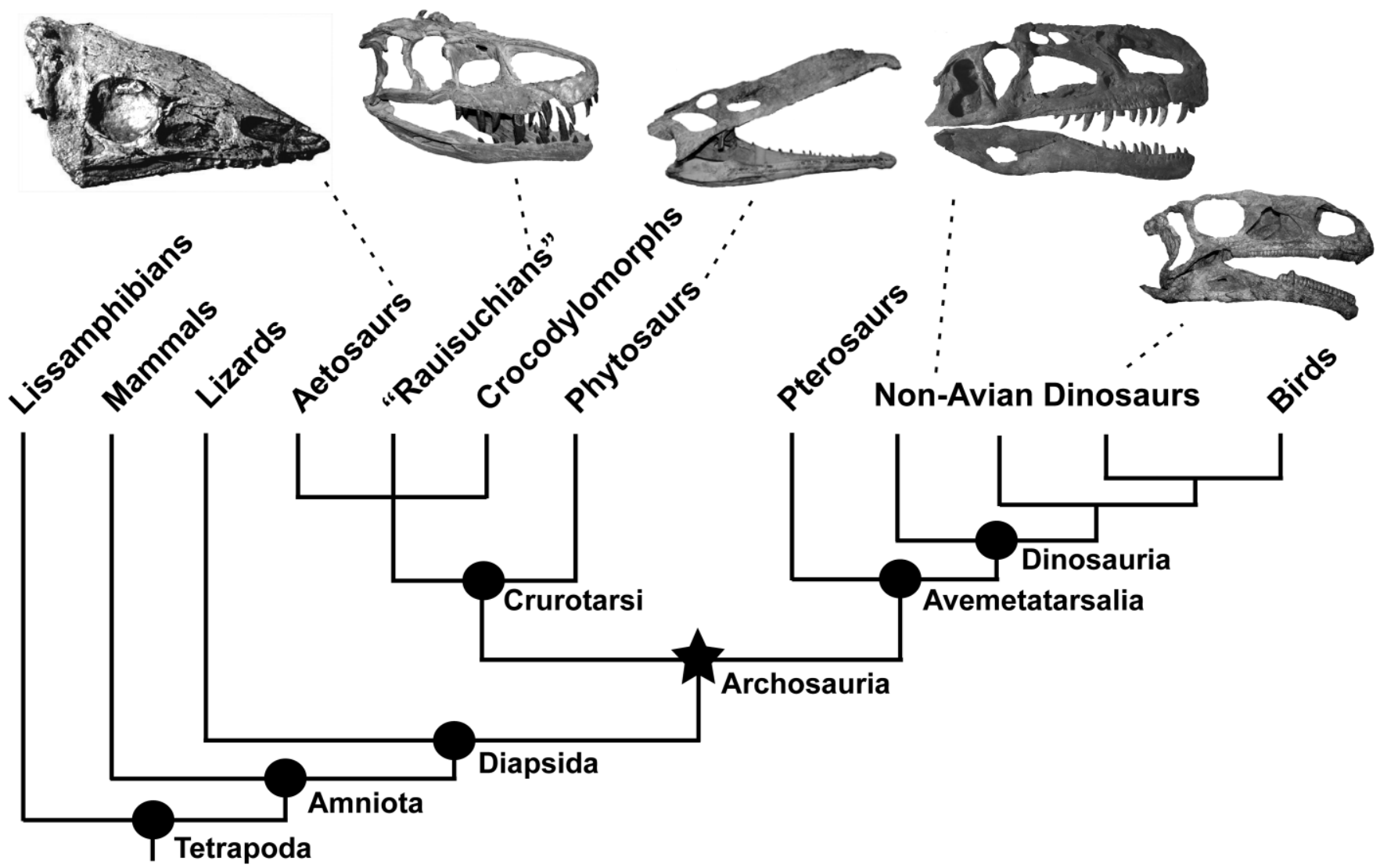

Figure 1 Framework phylogeny (genealogical tree) showing the position of archosaurs within the radiation of tetrapods (land-living vertebrates), along with basic ingroup relationships for major archosaur clades (based on Brusatte et al. 2010a and sources therein). Archosaurs are divided into two fundamental lineages: Crurotarsi (the 'crocodile-line') and Avemetatarsalia (the 'bird-line'). "Rauisuchians" may or may not comprise a monophyletic group. Aetosaurs, "rauisuchians", and crocodylomorphs are depicted as forming a polytomy. Aetosaurs and crocodylomorphs are found as sister taxa in the Brusatte et al. (2010a) phylogeny, but many other analyses recover "rauisuchians" and crocodylomorphs as closer relatives.

Sen 2005; Jalil \& Peyer 2007; Dzik et al. 2008; Nesbitt et al. 2010) and specimens belonging to entirely new, morphologically distinctive archosaur subgroups (Dzik 2003; Parker et al. 2005; Nesbitt \& Norell 2006; Li et al. 2006). Other significant fossils, long neglected or ignored, have been the subject of detailed morphological descriptions and reassessments (Benton 1999; Benton \& Walker 2002; Gebauer 2004; Nesbitt et al. 2007; Weinbaum \& Hungerbühler 2007; Brusatte et al. 2009). Comprehensive phylogenetic analyses, which synthesise anatomical data from new and old specimens alike, have been undertaken (Benton 1999; Irmis et al. 2007; Nesbitt 2009a, b; Nesbitt et al. 2009, 2010; Brusatte et al. 2010a). Finally, explicit numerical and statistical techniques have been used to assess evolutionary trends and patterns associated with the archosaur radiation (Brusatte et al. 2008a, b; Lloyd et al. 2008).

As a result of this landslide of new data, analyses, and techniques, the archosaur radiation can be examined in a more objective, rigorous manner than ever before. This paper summarises current knowledge on the origin and evolutionary radiation of archosaurs during the first 50 million years of the Mesozoic. Published studies are reviewed and new data are provided on archosaur diversity, lineage evolution, and morphological evolution during the Triassic and Early Jurassic. The aim is to provide a comprehensive, integrated picture of the earliest phase of archosaur history, with an emphasis on various discrete aspects of an evolutionary radiation such as taxonomic diversity, morphological variety, rates of morphological character evolution, and faunal abundance. Examination of each of these components, which may or may not be decoupled from each other, allows for a more lucid understanding of one of the most debated, profound, and classic examples of an evolutionary radiation in geological history.

\section{The archosaur radiation: a general background}

'Success' is a vague term whose meaning has long been pondered and debated in evolutionary biology. Archosaurs, however, are generally considered a 'successful' radiation of vertebrates for many reasons: they have persisted for hundreds of millions of years; have achieved a global distribution; are and have been exceptionally taxonomically diverse (at least by tetrapod standards); have occupied a range of body types and ecological niches; and are and have been locally abundant in individual faunas and ecosystems. The obvious question is why archosaurs (especially dinosaurs) have been able to achieve such success, and there has been no shortage of hypotheses and speculation (e.g., Cox 1967; Crompton 1968; Bakker 1971; Robinson 1971; Sill 1974; Halstead 1975; Charig 1980, 1984; Welles 1986). However, many of these hypotheses are extremely difficult, perhaps even impossible, to test. It is more instructive to step away from grand speculations and concentrate on quantifying trends and patterns, which objectively characterise the radiation just as statistics on profits, productivity and jobs describe a nation's economy. When these objective measurements are available, they may be marshalled as evidence in support of evolutionary processes and modes, just as economic statistics can be used to argue whether a certain time interval had a stronger or weaker economy than 
another, or support reasons why the economy improved or declined over a certain period. In short, it is important to quantify patterns first and infer processes later.

In reference to the archosaur radiation, several patterns are important to consider. First, it is essential to have some information on the major patterns of archosaur phylogeny: which archosaur taxa form clades, how these clades are related to each other, and when certain clades or lineages originated. A phylogenetic framework is also a necessary tool for quantifying other patterns, as archosaurs do not have a dense enough fossil record to use many non-phylogenetic methods that are often employed to study invertebrate groups (e.g. Foote 2001). Therefore, any thorough study on the archosaur radiation must begin with a phylogeny in hand.

Other important patterns to consider are taxonomic diversity, morphological disparity, absolute faunal abundance and rates of morphological character change. These can be assessed temporally (i.e. measuring them over time to look for peaks and declines) and also comparatively (i.e. compared in sister taxa or other comparable clades). Taxonomic diversity, often referred to as 'richness', refers simply to the number of taxa or lineages (species, genera, families, etc.), whereas morphological disparity is a measure of the variety of anatomical features, lifestyles, diets and ecological niches exhibited by a group. Absolute faunal abundance refers to the numerical dominance of organisms in an individual ecosystem or fauna, and rates of morphological character change measure how fast or how slowly organisms are evolving new anatomical features and modifying characters of their anatomy. These are all different measures (see Foote 1993, 1997; Brusatte et al. 2008a). For instance, a clade may be numerically dominant in an ecosystem, but all of these individuals may belong to the same species (low diversity) and have the same anatomical features (low disparity) (for a prime example of discordant macroevolutionary trends see Wing et al. (1993)). Therefore, it is important to quantify each of these different macroevolutionary patterns, which can then be compared and assessed to gain a more holistic picture of the evolutionary radiation of archosaurs.

Before going further, one caveat deserves comment. This discussion of the archosaur radiation takes a global perspective, and measures such as diversity, disparity and morphological rate are calculated for all archosaurs in general. It does not focus on macroevolutionary patterns on a regional scale, but other authors have begun examining how TriassicEarly Jurassic archosaur evolutionary patterns may have differed in different parts of the globe (e.g., Irmis et al. 2007; Nesbitt et al. 2007, 2009; Ezcurra 2010; Irmis 2011). As many archosaur faunas are better sampled and their ages more precisely constrained, such regional analyses will become increasingly powerful. Indeed, a major focus for future research will be extending coarser, global analyses to the finer, regional level.

\section{Archosaur phylogeny and lineage origination}

The higher-level phylogeny of archosaurs, especially the relationships of the extinct taxa that lived during the first 50 million years of archosaur history, has long been poorly understood. Several cladistic analyses have focused on Triassic and Early Jurassic archosaur phylogeny, which largely agree that the crown archosaur clade is divided into two major subgroups: Avemetatarsalia (essentially equivalent to a clade known as Ornithodira: including birds, dinosaurs, and their close relatives) and Crurotarsi (also known as Pseudosuchia: including crocodylomorphs and their extinct relatives, including phytosaurs, aetosaurs, ornithosuchids, and rauisuchians)
(Gauthier 1986; Benton \& Clark 1988; Sereno \& Arcucci 1990; Sereno 1991; Juul 1994; Bennett 1996; Benton 1999, 2004; Irmis et al. 2007; Nesbitt et al. 2009, 2010; Brusatte et al. 2010a). Beyond this, however, many disagreements have persisted, including debates over which crurotarsan clade is most basal, which taxa are the closest relatives of crocodylomorphs, and whether or not rauisuchians form a monophyletic group (Parrish 1993; Benton \& Walker 2002; Gower 2002; Nesbitt 2003, 2007; Nesbitt \& Norell 2006; Weinbaum \& Hungerbühler 2007; Brusatte et al. 2010a).

Recent years have brought a renewed focus on basal archosaur phylogeny, bolstered by the deluge of new archosaur specimens and redescriptions of neglected fossils over the past decade. Several independent research groups have been working on archosaur phylogeny, and three large-scale analyses have been published recently (Irmis et al. 2007; Nesbitt et al. 2009; see also Nesbitt et al. 2010; Brusatte et al. 2010a; see also Brusatte 2007). In particular, the Brusatte et al. (2010a) analysis includes 20 rauisuchian genera, allowing a stronger test of rauisuchian monophyly than previously possible, as well as a greater understanding of the ingroup relationships of these poorly understood crocodile relatives. The cladogram presented by Brusatte et al. (2010a) is shown in Figure 2 .

An even larger and more comprehensive phylogeny of basal archosaurs was recently conducted by Sterling Nesbitt as part of his PhD dissertation (Nesbitt 2009a), and the results have been presented briefly in an abstract (Nesbitt 2009b) and in this volume (Nesbitt et al. 2011). As Nesbitt's (2009a, b) phylogeny is first published in detail in this volume it will not be discussed here, but it promises to remain a benchmark study for years to come. In the meantime, we rely on the phylogeny of Brusatte et al. (2010a) as a framework for these studies of the archosaur radiation, as it is the most comprehensive available, and was compiled by the present authors' research group (Fig. 2). It should be noted, however, that Nesbitt's phylogeny is different in several regards to that of Brusatte et al. (2010a), specifically in the placement of phytosaurs and aetosaurs and the recovery of a non-monophyletic Rauisuchia. Therefore, future macroevolutionary analyses utilising Nesbitt's phylogeny may yield different results than those presented here.

The oldest unequivocal crown-group archosaur with a wellconstrained phylogenetic position is Xilosuchus, a crurotarsan from the Olenekian Heshanggou Formation (ca. 249 million years old) of China (Nesbitt et al. 2011). Xilosuchus shares several unusual features of the skull and vertebrae with poposauroid crurotarsans such as Poposaurus and Shuvosaurus, and has been recovered as a member of the poposauroid clade by Nesbitt et al. (2011). Therefore, Xilosuchus is not only a crurotarsan, but a member of a derived subclade. As such, numerous other, more basal, lineages of archosaurs must have also been present by the Olenekian by virtue of phylogenetic ghost range extensions (Smith 1988; Norell 1992). These lineages include the bird line (Avemetatarsalia), as well as several major crurotarsan lineages such as phytosaurs, aetosaurs, many rauisuchian ingroup clades and, potentially, crocodylomorphs. It is likely that these lineages can be extended back even further, however, as trace fossils from archosaurs or close outgroups are known from earlier in the Olenekian (ca. 249-251 million years ago; Fuglewicz et al. 1990; Haubold 1999; Ptaszyński 2000; Melchor \& Valais 2006; Klein \& Haubold 2007; Niedźwiedzki \& Ptaszyński 2007; Diedrich 2008; Kubo \& Benton 2009). However, the first observed fossils of many of these lineages do not appear until much later in the fossil record, usually the Carnian or Norian (approximately 10-30 million years younger than Xilosuchus). 


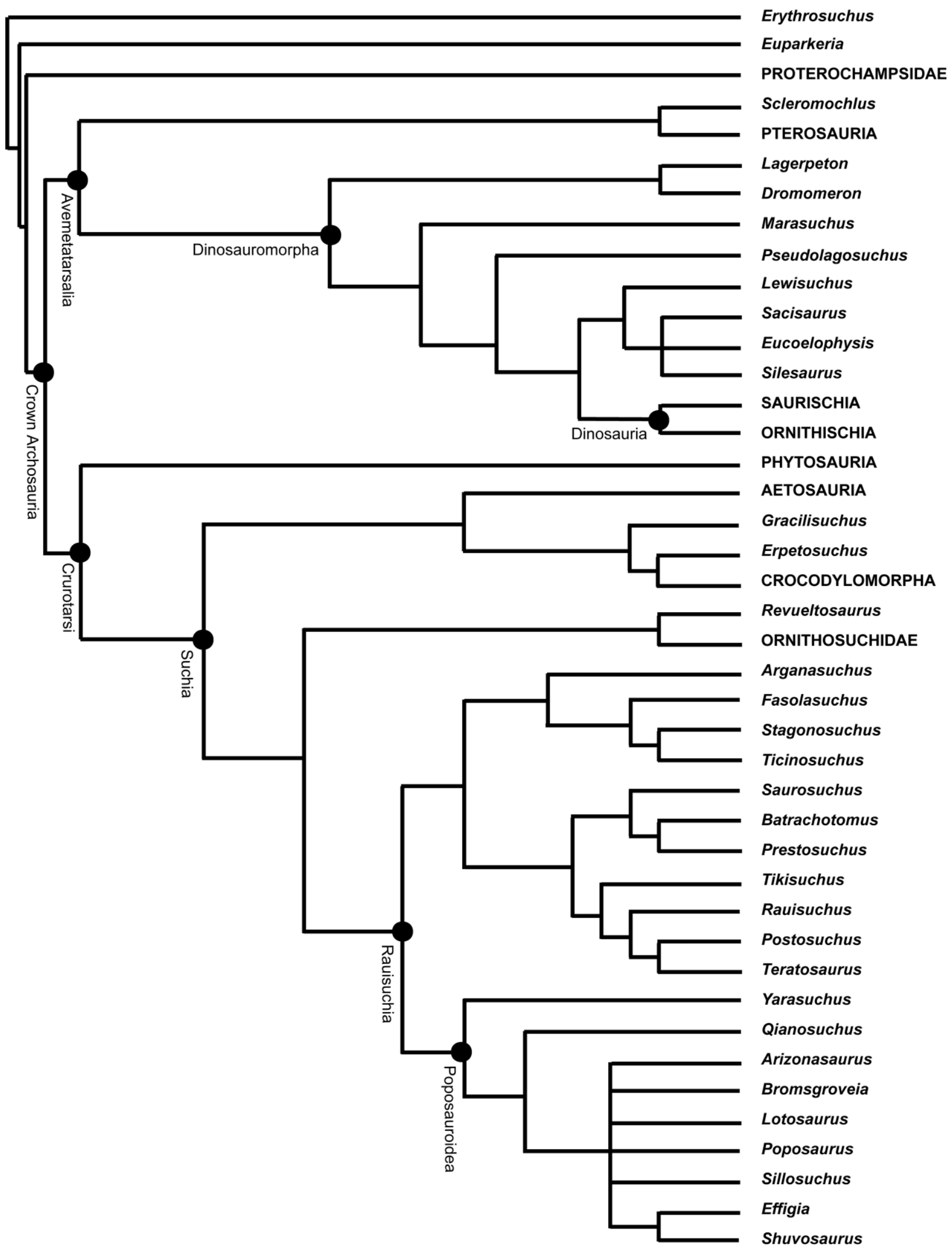

Figure 2 The higher-level phylogeny of archosaurs presented by Brusatte et al. (2010a). Names next to nodes denote major clades. This phylogeny is used as a framework for many of the macroevolutionary analyses discussed in this paper. For further details on the phylogeny, including the data and search algorithms used to construct it, please see the original publication.

In summary, the archosaur clade originated early in the Triassic and many key archosaur lineages originated long before their first fossils are known (see Brusatte et al. 2010a for an overview and Müller \& Reisz 2005 and Benton \& Donoghue 2007 for archosaur origination estimates). The paucity of archosaur fossils in the Early-Middle Triassic, and the complete lack of fossils from some lineages that must have been present, is puzzling. This may result simply from a biased fossil record, but several Early-Middle Triassic units are well sampled and have yet to yield unequivocal archosaur fossils 
(e.g. Shubin \& Sues 1991). In the redbeds of Russia, perhaps the best sampled region for Permo-Early Triassic terrestrial fossils, archosaurs and their close relatives are rare in the earliest Triassic, despite this time interval being the most intensively sampled, in terms of numbers of localities explored and specimens collected, in a major faunal census (Benton et al. 2004). Therefore, it is possible that the rarity of EarlyMiddle Triassic archosaur fossils reflects a genuine evolutionary signal. The major archosaur lineages were undoubtedly present during most of the first 20 million years of the Triassic, but perhaps were rare components of faunas (low faunal abundance) and exhibited low raw diversity, and were also perhaps geographically restricted, thus explaining their elusive early fossil record. This hypothesis can be tested only with future discoveries, but what is undeniable is that many fundamental archosaur lineages had originated by the Olenekian, and perhaps even earlier.

\section{Archosaur diversity: clade and lineage evolution}

The major archosaur lineages were established by the EarlyMiddle Triassic, but the mere presence of a group (or in this case, several groups) does not necessarily mean that it contained a large number of species. The term 'diversity' in most palaeontological studies refers to the number of species (=species richness) or other higher-level taxa (genera, families, major clades, etc.) within a certain time period, place, or group. Two important patterns to examine are diversity over time (in this case, archosaur diversity across the Triassic-Early Jurassic) and the shape of the phylogenetic tree (in this case, whether some archosaur subclades have significantly more species than other clades). Quantifying these patterns can pinpoint major intervals of diversification during the first 50 million years of archosaur history and specific clades or lineages that are exceptionally species rich.

\subsection{Raw diversity counts}

Counts of archosaur diversity over the Triassic and Early Jurassic have yet to be presented, although archosaurs from this time have been included in larger studies of tetrapod diversity and extinction (e.g. Benton 1986a, b, 1994). We here present a compilation of archosaur diversity over time (Fig. 3), based on a database compiled by MJB (available from the author on request). Both observed and phylogeneticallycorrected (sensu Norell 1992, see caption for details) curves are presented. Phylogenetic corrections should be considered minimal estimates, however, as many Triassic and Early Jurassic archosaur taxa have yet to be included in phylogenetic analyses. Taxon ages are based on the Gradstein et al. (2004) and Walker \& Geissman (2009) timescales, modified to include a longer Rhaetian (following Muttoni et al. 2010). This time scale depicts a longer Norian than previously considered (following Muttoni et al. 2004; Furin et al. 2006), and as a result many taxa formerly assigned a late Carnian age, equivalents of the Ischigualastian or Adamanian tetrapod biochrons, are now considered early Norian (e.g. Irmis and Mundil 2008).

Both crurotarsans and avemetatarsalians, and thus archosaurs as a whole, exhibited low diversity throughout the Middle Triassic, with a slight increase in the Carnian and a large spike in the Norian (Fig. 3). All three groups exhibited a profound diversity decrease between the Norian and the Rhaetian, and diversity fluctuated around Rhaetian levels for the entire Early Jurassic. The most conspicuous pattern in all curves is the great Norian diversity increase. This may partially reflect a bias of uneven time bins, as the Norian is by far the longest time interval in the curve $(\sim 20$ million years long, and approximately 15 million years longer than the second-longest interval). However, statistical analysis indicates that there is only a weak correlation between diversity and time bin duration (see caption to Fig. 3). Therefore, based on current data, the Norian can be regarded as a good candidate for a time of major archosaur diversification. It is currently difficult to perform a diversity analysis in which time bins are equalised, due to poor age constraints on most Triassic-Early Jurassic terrestrial formations, but such analyses should be possible as the time scale is further refined and formations are dated and correlated with more confidence.

The large drop between the Norian and Rhaetian is more difficult to interpret. It is possible that this decrease is an artefact of poor dating of continental strata, as very few terrestrial formations (and therefore their fossils) are dated as Rhaetian, despite the fact that the upper parts of units such as the Chinle Formation very well could belong to this stage (R. B. Irmis, pers. comm. 2010). If this drop is real, it is unclear whether it reflects a true diversity 'crisis' (e.g. Benton 1986a; Langer et al. 2010) or a backwards smearing of end-Triassic extinctions, and untangling these possibilities will require better age resolution and more complete fossil sampling.

Crurotarsans and avemetatarsalians exhibit similar curves, but with some subtle differences. Crurotarsans were more diverse during the Anisian, Ladinian and Carnian, but from the Norian onwards avemetatarsalians were the more diverse clade, mainly as a result of the great diversification of dinosaurs. Crurotarsans show a greater diversity spike between the Ladinian and Carnian than avemetatarsalians, which were almost equally diverse in both intervals. Avemetatarsalians also lost fewer taxa total, as well as a lower percentage of taxa, between the Norian and Rhaetian.

These curves are provocative, but further work is needed to clarify the true patterns of archosaur diversity during the Triassic and Early Jurassic. First, as the Triassic time scale is further refined and more radioisotopic dates become available, taxa can be assigned to specific time intervals with more confidence. Secondly, as phylogenetic analyses proliferate, phylogenetic corrections can be carried out more rigorously, and fragmentary fossils, which are important to include in diversity assessments, can be assigned to Archosauria or constituent subclades more reliably (see Fara 2004). Thirdly, it is becoming increasingly evident that diversity counts are strongly biased by the rock record, and intervals of high diversity are often merely those with a more complete fossil record than less diverse time periods (e.g. Peters \& Foote 2001; Smith 2001; see Barrett et al. 2009 for an example relevant to Mesozoic archosaurs). Therefore, understanding potential sampling biases is critical.

There has been no attempt in the present paper to statistically control for sampling biases, but the results can be interpreted based on terrestrial rock record compilations recently presented by Fröbisch (2008) and Barrett et al. (2009) in studies of anomodont and dinosaur diversity, respectively. These curves depict the number of anomodont and dinosaurbearing terrestrial formations, a proxy for the available outcrop that may preserve fossils. Most importantly, these studies suggest that a similar number of Carnian and Norian formations have been sampled, indicating that the great spike in Norian archosaur diversity is not simply an artefact of a more complete record during that interval (note, however that some recent revisions to the Triassic timescale, and revised temporal assignment of formations, have not been fully incorporated by these authors, as this information was unavailable at the time these papers were written). However, the Barrett et al. (2009) curve shows that substantially fewer Rhaetian formations have been sampled than Norian units, which may partially be 
driving the observed Rhaetian diversity decrease. There are many more Early Jurassic formations than Late Triassic units, however, so the relatively lower diversity during the Early Jurassic is likely a real signal, following diversity losses at the end-Triassic extinction and not sampling bias. It is stressed that these are only rough interpretations based on published rock record curves, but an increased understanding of Triassic-Early Jurassic faunas and more precise correlations and age assessments of important formations should permit sampling-standardised diversity profiles, as has recently been done for other Mesozoic tetrapods (Lloyd et al. 2008; Barrett et al. 2009; Benson et al. 2010).

\subsection{Diversification in a phylogenetic context}

Along with assessing whether certain time periods supported more diversity than others, it is also interesting to ask whether
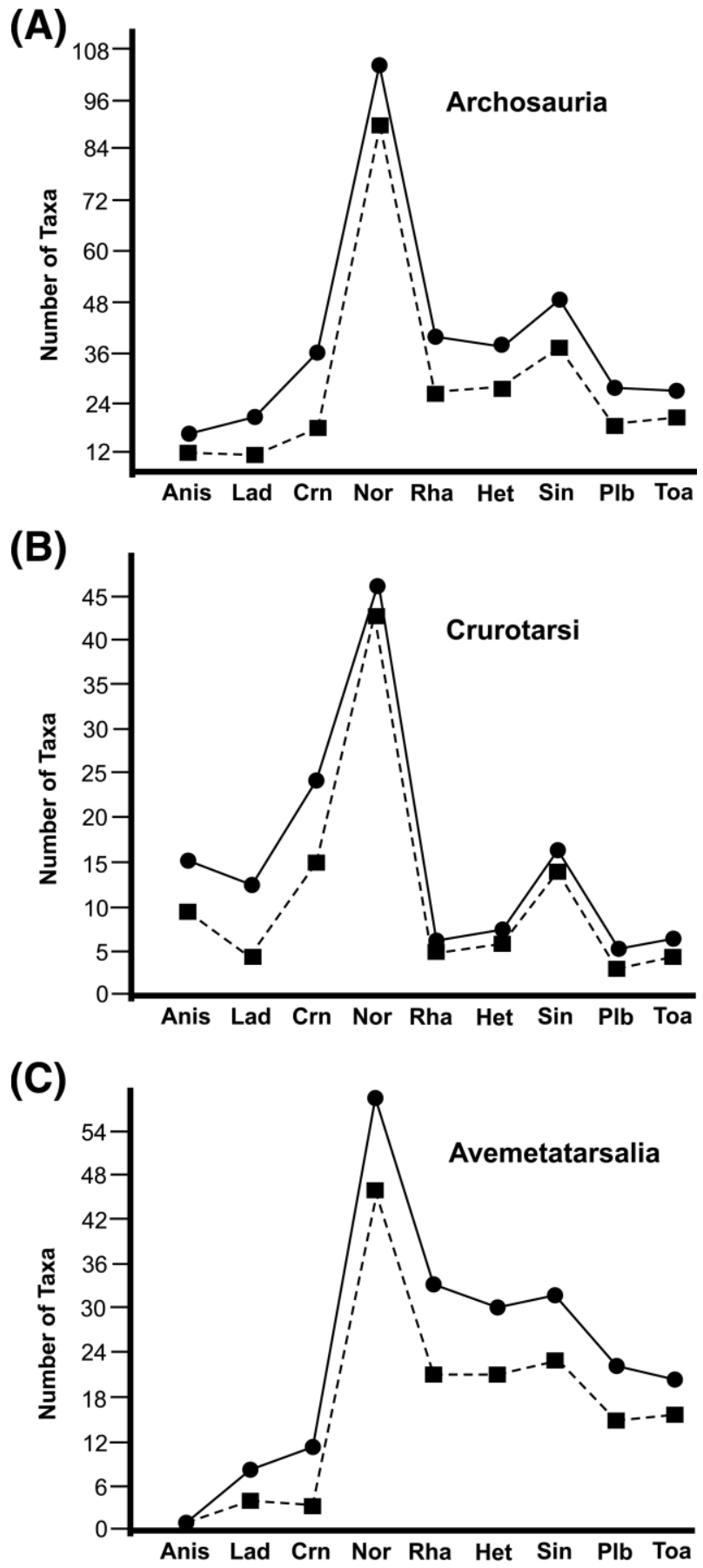

certain clades are more diverse than others, and whether these differences are statistically significant. Once these exceptionally diverse clades are identified, it can be observed whether they are concentrated in a certain part of the archosaur cladogram or in a certain time interval. Such questions have been addressed by only a handful of studies in the vertebrate palaeontology literature (Ruta et al. 2007; Lloyd et al. 2008; Tsuji \& Müller 2009).

In order to label a clade as 'exceptionally diverse', it must be shown that the group in question is more diverse than predicted by chance. One way to do this is to compare an observed cladogram with a null expectation for how lineages should ideally split over time if such splitting is random. This null expectation is usually based on an equal-rates birth-death model, which assumes that each lineage has an equal, but independent, probability of splitting at any given time (see Chan \& Moore 2002, Nee 2006, Ricklefs 2007 and Purvis 2008 for more details). Ideally, these tests should be carried out on a complete or near-complete, species-level tree, as each terminal taxon must be equivalent (i.e. of the same 'rank'; see Jones et al. 2005). The program SymmeTREE (Chan \& Moore 2005) uses a likelihood ratio test to calculate a delta shift statistic $\left(\Delta_{2}\right)$ for each node in the phylogeny, which assesses the likelihood that one sister taxon is significantly more lineagerich than the other. The probability of the shift statistic is calculated by comparing the observed statistic with a randomised distribution of statistics for 100,000 trees of the same size (number of taxa) generated by the null birth-death model. Therefore, each node in the phylogeny has a probability associated with it, and if these probabilities are significant (i.e. if the observed $\Delta_{2}$ statistic falls within the upper $5 \%$ tail of the randomised distribution), the clade stemming from that node can be considered as 'exceptionally diverse'. Oftentimes such clades are described as having a 'significant diversification shift' at their bases.

The present authors carried out a novel analysis of Triassic-Early Jurassic archosaur diversification by assembling an informal supertree (sensu Butler \& Goswami 2008) of all archosaur genera that have been included in recent

Figure 3 Plots of archosaur diversity (counts of genera) over time, from the Anisian to the Toarcian. Squares and dashed lines represent observed genera, whereas circles and solid lines represent total genera (observed plus inferred from phylogenetic ghost lineages and ranges, see below). (A) all crown group archosaurs; (B) crurotarsan archosaurs; (C) avemetatarsalian archosaurs. Abbreviations on the $\mathrm{x}$-axes represent Middle Triassic-Early Jurassic stages: Anis=Anisian; Lad=Ladinian; $\mathrm{Crn}=$ Carnian; Nor $=$ Norian; Rha $=$ Rhaetian; Het $=$ Hettangian; Sin=Sinemurian; $\mathrm{Plb}=$ Pliensbachian; Toa $=$ Toarcian . Phylogenetic corrections based on the following phylogenies: higherlevel Archosauria (Brusatte et al. 2010a); Aetosauria (Parker 2007); Crocodylomorpha (Clark et al. 2004); Dinosauria (Langer \& Benton 2006; Butler et al. 2007; Smith et al. 2007; Upchurch et al. 2007); Phytosauria (Hungerbühler 2002); Pterosauria (Kellner 2003). In all cases, taxa are assigned to all time bins that comprise their finest age resolution. Statistical analyses indicate that there is only a weak correlation between archosaur diversity and the temporal duration of stage-length bins (observed diversity: Pearson's $r=0.916, p=0.005$; Spearman's $r_{s}=0 \cdot 207, p=0 \cdot 606$; Kendall's $\tau=0 \cdot 133, p=0 \cdot 684$; phylogenetically corrected diversity: Pearson's $r=0.916, p=0.005$; Spearman's $r_{s}=0 \cdot 310, p=0 \cdot 446$; Kendall's $\tau=0 \cdot 261, p=0 \cdot 46$ ). Correlations are significant with simple linear correlation (Pearson's $r$ ), but are insignificant with alternative methods (Spearman's $r_{s}$ and Kendall's $\tau$ ). The discordance between simple linear correlation and other methods is intriguing, and likely results from the fact that the Norian is much longer than other time intervals and has the highest observed diversity. With this in mind, when the Norian is excluded and the remaining eight stages are assessed, there is virtually no simple linear correlation between stage duration and diversity (observed diversity: Pearson's $\mathrm{r}=-0.02, \quad \mathrm{p}=0.97$; phylogenetically corrected diversity: $\mathrm{r}=0 \cdot 06$; $\mathrm{p}=0 \cdot 88)$. 


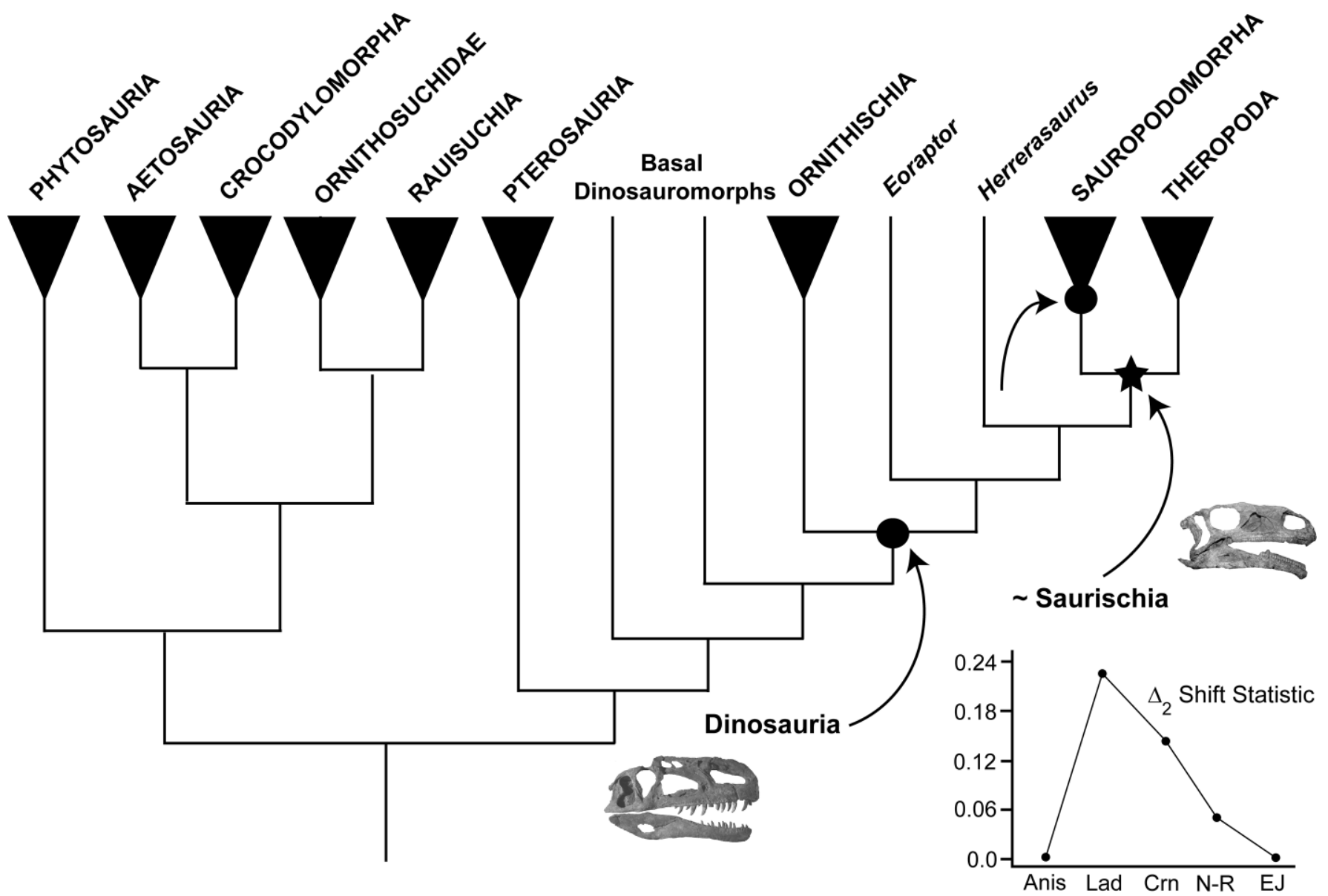

Figure 4 Simplified version of the informal archosaur supertree (see text), with arrows indicating those clades that are more species-rich than predicted by chance (i.e., those that have a 'significant diversification shift' at their bases). The star indicates the one significant clade, Saurischia minus Herrerasaurus and Eoraptor $\left(\Delta_{2}\right.$ shift statistic $=2.89037 ; p=0.039886)$. The circles indicate the two marginally significant clades, Dinosauria $\left(\Delta_{2}\right.$ shift statistic $=2.07944 ; p=0.0606613)$ and Sauropodomorpha $\left(\Delta_{2}\right.$ shift statistic $\left.=1.38629 ; p=0.110784\right)$. All three clades with exceptional species richness are dinosaur clades, and no such clades are found within Crurotarsi. Triangles represent major archosaur subclades whose ingroup relationships are collapsed for simplicity in this figure, but are represented by a full range of genera in the analysed tree. Plot in the bottom right-hand corner depicts the mean $\Delta_{2}$ shift statistic over time (clades binned according to first sampled descendant). These differences are generally not significant: of all pairwise comparisons between time bins, only the Ladinian and Early Jurassic are significantly different (Mann-Whitney U test; $\mathrm{U}=285, p=0 \cdot 0421$ ).

phylogenetic analyses. As almost all genera are monospecific, they are proxies for species. The strict consensus tree of higher-level archosaur phylogeny presented by Brusatte et al. (2010a) was used as a framework, onto which ingroup relationships of several subgroups were grafted. These ingroup relationships were taken from: Aetosauria (Parker 2007); Crocodylomorpha (Clark et al. 2004); Dinosauria (Langer \& Benton 2006; Butler et al. 2007; Smith et al. 2007; Upchurch et al. 2007); Phytosauria (Hungerbühler 2002); and Pterosauria (Kellner 2003). In total, this tree included 110 taxa and 200 nodes, with all polytomies treated as 'soft' in the statistical analyses.

When subjected to analysis in SymmeTREE, only a single clade, the group of saurischian dinosaurs minus the basal taxa Herrerasaurus and Eoraptor, is found to be significantly more diverse than expected by chance (Fig. 4). Two other nodes exhibit marginally significant shifts: Dinosauria and Sauropodomorpha (Fig. 4). When the mean delta shift statistic $\left(\Delta_{2}\right)$ is plotted over time, it is seen that the Anisian was a period of relatively low lineage diversification, followed by a spike in the Ladinian and a decline across the Triassic and Early Jurassic (Fig. 4). However, these differences are generally not significant (Fig. 4 caption), and thus there is no clear pattern of significant diversification events over time. In other words, significant lineage splitting among basal archosaurs is not concentrated in one interval.

These patterns have several implications. First, clades that are more species rich than expected by chance are rare among basal archosaurs, suggesting that most of archosaur evolution in the Triassic and Early Jurassic is indistinguishable from a random model of lineage splitting. However, all nodes with significant or marginally significant diversification shifts fall within the dinosaur clade. On the contrary, no crurotarsan clades are exceptionally diverse. Archosaur diversification, measured in a whole-tree phylogenetic context, appears to have been relatively static across the Triassic and Early Jurassic. However, the low Early Jurassic $\Delta_{2}$ value is probably partially an artefact of edge effects, as lineages that must have been present during this time because they are known from the Middle or Late Jurassic, but are unsampled in the fossil record, are not included in this supertree. Additionally, it could be argued that the lack of any significant clades within Crurotarsi is an artefact of sampling, as many crurotarsan clades have been the subject of less phylogenetic study than dinosaurs, and thus many known taxa have yet to be studied phylogenetically and are excluded from the supertree. Only additional studies can bear on this issue. 


\section{(a) LATE TRIASSIC}

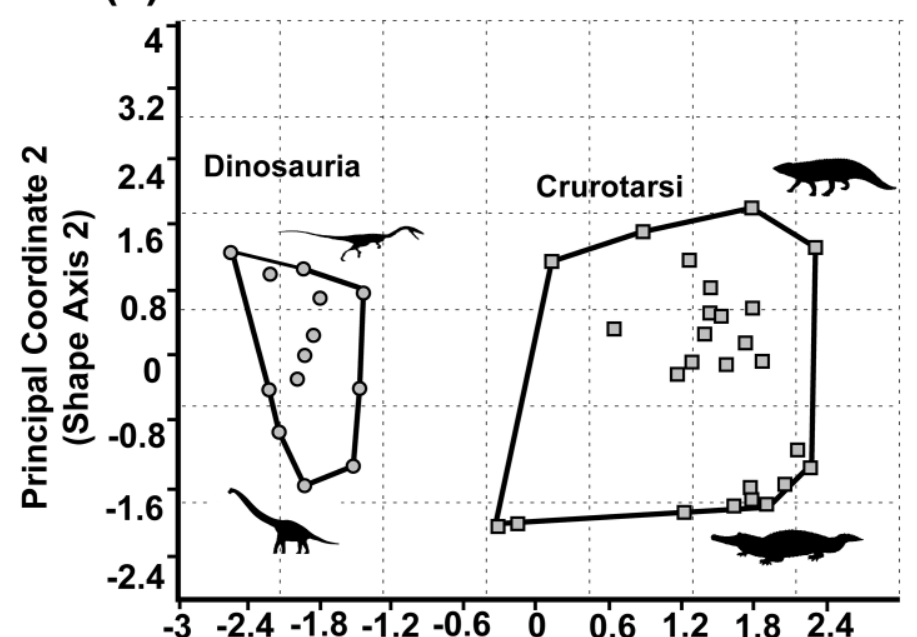

(b) EARLY JURASSIC

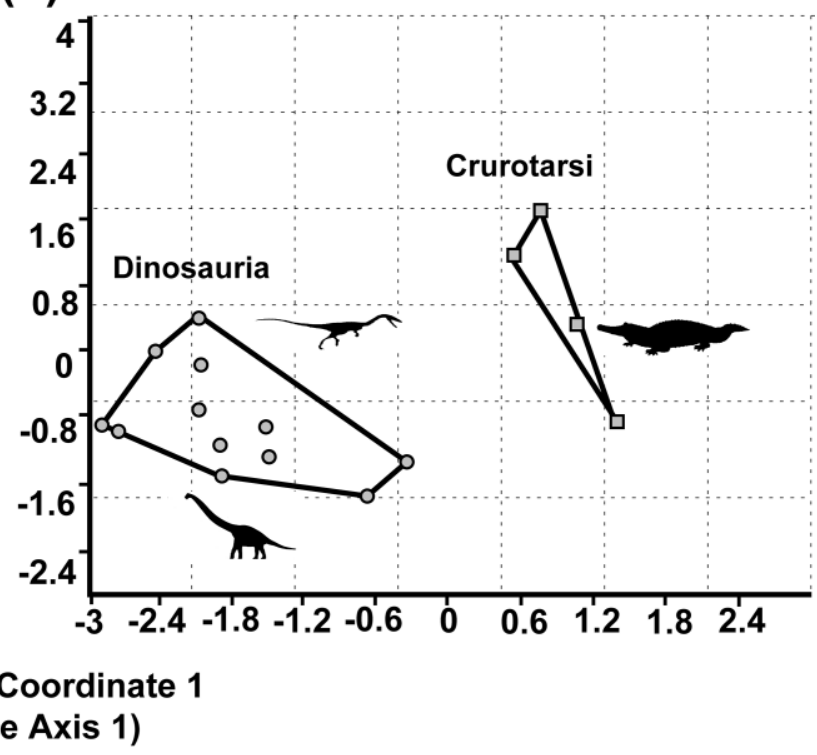

Figure 5 Morphospace plots for archosaurs in the (a) Late Triassic (Carnian-Norian) and (b) Early Jurassic (Hettangian-Toarcian), modified from Brusatte et al. (2008b). For simplicity only the first two principal coordinates (shape axes) are shown, and only dinosaurs and crurotarsans are illustrated (pterosaurs and non-dinosaurian dinosauromorphs are deleted). Crurotarsans had a larger morphospace than dinosaurs in the Late Triassic, but these roles were reversed in the Early Jurassic. Dinosaur morphospace only slightly increased in the Early Jurassic, whereas crurotarsan morphospace occupation crashed. These differences are statistically significant and borne out by the quantitative disparity analysis that takes into account information from all principal coordinate axes (see text).

\section{Archosaur morphological evolution: disparity, amount of change and rates}

Morphological evolution is distinct from cladogenesis (lineage splitting and evolution). The development of novel body plans or high rates of character or size evolution need not correspond with the rate of new species formation or significant diversification shifts on the cladogram, although in some cases rates of cladogenesis and morphological evolution may be correlated (e.g. Adams et al. 2009). Therefore, it is imperative to compare measures of cladogenesis with certain aspects of morphological evolution. Two fundamental components of morphological evolution are especially informative: morphological disparity and rates of discrete character change. Disparity measures the variety of morphological evolution, by quantifying the range or spread of body types and morphologies exhibited by a group of organisms (Gould 1991; Wills et al. 1994; Foote 1997; Erwin 2007). Rates analysis quantifies the amount and speed of morphological evolution, by assessing how many characters change during a certain time interval (Wagner 1997; Ruta et al. 2006). Although it may be intuitive to expect disparity and rates to be concordant with each other (in other words, for high rates of character change to translate into a high variety of body types), empirical studies (Brusatte et al. 2008a; Adams et al. 2009) and theoretical considerations (O’Meara et al. 2006; Ricklefs 2006; Sidlauskas 2007) show that this is not always the case.

\subsection{Disparity: morphospace and anatomical variety}

Morphological disparity is a measure of the diversity of anatomical features and body types exhibited by a group, which may sometimes be considered as a proxy for ecological variety (lifestyles, diets, niche occupation, etc.), because the latter usually, but not always, predicts the former. Disparity can be measured in many ways, using either morphometric (shape) data or discrete characters, which are assessed for a large number of organisms in order to quantify the overall variety in their morphological features. Once compiled, these large datasets are subject to multivariate statistical analyses, which combine and distil the numerous anatomical observations into a smaller and more manageable set of scores for each taxon. These scores enable the taxa to be plotted into a morphospace - a 'map' of morphologies which graphically represents the spread of anatomical features - and permit the calculation of various statistics that quantify whether certain clades or time intervals are significantly more disparate than others. The two most useful and intuitively understandable statistics are range and variance. Range measures the entire spread of morphological variation (the size of morphospace occupied by the group), whereas variance measures the spread of the group in morphospace about its centre. The concept of morphological disparity is deeply entrenched in the macroevolution literature, although infrequently assessed for vertebrate groups, and useful primers have been presented by Wills et al. (1994), Foote (1997), Ciampaglio et al. (2001) and Erwin (2007).

Triassic and Early Jurassic archosaurs are one of the few vertebrate groups that have been subjected to disparity analysis. Brusatte et al. (2008a) measured the disparity of archosaurs across the Triassic, and this analysis was expanded to include Early Jurassic taxa in a subsequent publication (Brusatte et al. 2008b; morphospace plots in Fig. 5). However, because of space limitations, Brusatte et al. (2008b) only presented disparity curves for individual archosaur ingroup clades (Avemetatarsalia, Crurotarsi, and Dinosauria), and did not graphically depict the disparity of Archosauria as a whole across the Triassic and Early Jurassic. A curve illustrating the morphological range of all archosaurs is presented here (Fig 6A), and variance statistics were also compiled but are not presented graphically. There was a significant increase in disparity between the Middle and Late Triassic (i.e. between the Ladinian and Carnian), as was also found in the initial analysis of Brusatte et al. (2008a). Range measures show a marginally significant increase between the Carnian and Norian, but 
(A)

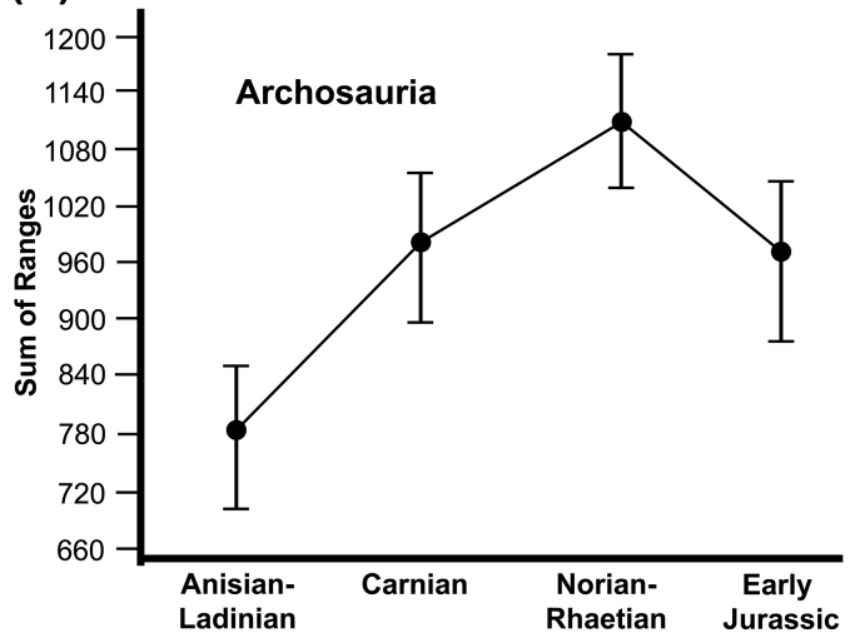

(B)

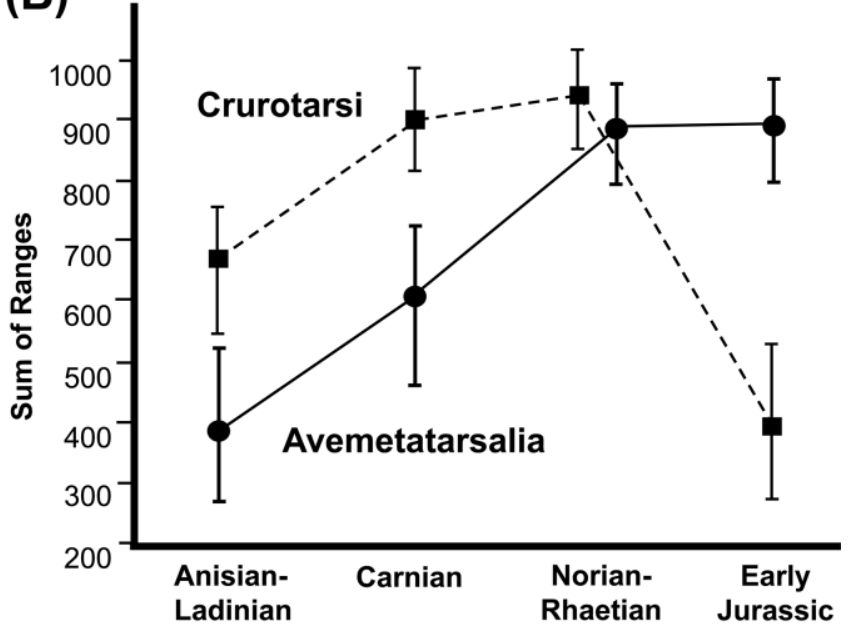

Figure 6 Plots of archosaur disparity (morphological variety) over time, from Brusatte et al. (2008b). Disparity is measured as the sum of ranges on the first 65 PCO axes; alternative measures (product of ranges, sum/product of variances) give similar results, as reported in Brusatte et al. (2008b). Anisian and Ladinian taxa are combined here to make sampling more even between bins, but see Brusatte et al. (2008a) for separate Anisian and Ladinian measures from a slightly different dataset. (A) all crown-group archosaurs; (B) crurotarsan and avemetatarsalian archosaurs. Error bars represent 95\% bootstrap confidence intervals, and non-overlapping error bars indicate a significant difference between two time-bin comparisons.

variance measures of these two time bins are statistically indistinguishable. Similarly, range statistics, but not variance metrics, exhibit a marginally significant decrease from the Norian to the Early Jurassic. Unfortunately, because few fossils are assigned a Rhaetian age (see above), the Norian and Rhaetian are binned together, and it is currently not possible to determine whether there was a significant change in disparity between these two intervals, or whether the substantial decrease between the Late Triassic and Early Jurassic is partially an artefact of this binning approach.

The morphological disparity of certain archosaur ingroup clades is also important to consider (Fig. 6B). Brusatte et al. $(2008 \mathrm{a}, \mathrm{b})$ calculated the disparity of three ingroup clades: Avemetatarsalia, Crurotarsi, and Dinosauria. The goal of this exercise was twofold. First, examining the disparity of ingroup clades can help untangle which taxa were largest contributors to the overall pattern of archosaur disparity over time. Secondly, one of the great revelations of the recent renaissance in Triassic-Early Jurassic archosaur palaeontology is that dinosaurs and several crurotarsans were strongly convergent on each other (Parker et al. 2005; Nesbitt \& Norell 2006; Nesbitt 2007). These two groups lived alongside each other and likely filled similar niches for tens of millions of years, and it is reasonable to consider them as 'competitors'. Therefore, comparing the disparity of crurotarsans and dinosaurs (or avemetatarsalians as a whole) may shed light on large-scale patterns of faunal replacement and competitive dynamics between the groups.

The most striking finding of the Brusatte et al. (2008a) study is that crurotarsans were twice as disparate as dinosaurs during the Late Triassic, and this difference is statistically significant. In other words, crocodile-line archosaurs had twice the variety of body plans, lifestyles, and diets as dinosaurs during the first 25-30 million years of dinosaur history. This result also holds if strict sister taxa, in this case Crurotarsi and Avemetatarsalia, are compared. Crurotarsan disparity was invariably higher than dinosaur disparity during the Triassic (Brusatte et al. 2008a, b). There was a significant jump in crurotarsan disparity between the Middle and Late Triassic, but Carnian and Norian crocodile-line taxa had indistinguishable levels of disparity. However, there was a profound and significant decrease in crurotarsan disparity from the Norian to the Early Jurassic (although see Brusatte et al. (2010b) for a discussion of how this decrease may be exaggerated because of exclusion of some disparate, latest Early Jurassic crocodylomorphs in the analysis). Dinosaurs, on the other hand, exhibited their significant disparity increase between the Carnian and Norian, whereas Norian and Early Jurassic disparity levels are statistically indistinguishable (Brusatte et al. 2008a, b).

These patterns have several implications. First, there is no evidence that dinosaurs were outcompeting crurotarsans across the Late Triassic: crurotarsans explored a wider range of morphospace; their disparity was invariably higher than that of dinosaurs; and there were no coupled trends showing dinosaur disparity increasing at the expense of crurotarsans. Secondly, the radiation of both crurotarsans and dinosaurs/ avemetatarsalians in the Late Triassic contributed to the overall archosaur pattern of increasing disparity between the Middle and Late Triassic. However, the marginally significant increase in archosaur disparity between the Carnian and Norian was driven mostly by the evolution of new dinosaur taxa, as dinosaurs exhibited a significant increase between these two stages, whereas crurotarsan disparity remained static across the Late Triassic. Thirdly, the dynamic of archosaur disparity changed greatly in the Early Jurassic, in the aftermath of the end-Triassic extinction event. Up to this point crurotarsans had been more disparate than dinosaurs, but in the Early Jurassic these roles were reversed. Dinosaurs (and avemetatarsalians) were now significantly more disparate than crurotarsans, a pattern driven by an overwhelming crash in crurotarsan disparity across the Triassic-Jurassic boundary, presumably due to the extinction of phytosaurs, aetosaurs, ornithosuchids and rauisuchians. Dinosaur disparity did not increase significantly in the Early Jurassic, despite the availability of niches once occupied by crurotarsans, but dinosaurs weathered the storm and maintained their Late Triassic disparity levels in the Early Jurassic. Afterwards, they presumably increased their disparity as they extended their modes of life and proportion of ecospace occupation through the Middle and Late Jurassic, a proposition that is yet to be tested.

\subsection{Rates of character change: the amount and tempo of morphological evolution}

Disparity measures the variety of morphological evolution, but it is also informative to consider two other aspects of phenotypic change: the amount and the speed of morphological evolution. Variety and amount may intuitively seem related, 
but they are distinct measures. Variety is a purely phenetic concept that assesses the similarities and differences of observed morphologies. Amount, on the other hand, is a phylogenetic concept that takes into account the character changes, including reversals, that have resulted in an observed morphology. Two animals may have exactly the same morphologies say, a deep skull, conical teeth, and a long tail. Therefore, there is no morphological variety between them and they would plot at the same point in morphospace. However, perhaps one animal evolved from an ancestor with a shallow skull, thin teeth, and a short tail (three character changes), whereas the other evolved from an ancestor with a deep skull, conical teeth, and a short tail (one character change). In this case, the amount of evolution (one vs. three changes) differs between the two animals even though they look exactly the same. In this example, the speed of evolution may also differ between the two animals. Even though they look the same, one animal may have evolved its morphological features over a shorter period than another, and hence underwent more change in a shorter amount of time (i.e. a higher rate of evolution).

Morphological amounts and rates are measured in a phylogenetic context, because it is necessary to know the sequence of character change on the lines to observed morphologies and how much time has occurred between branching or speciation events (although see Foote (1997) for alternative methods that do not explicitly require a phylogeny, but are less powerful in identifying rate shifts). In other words, researchers must have information on how many characters change on each branch of the tree and over what length of time that branch existed (hence, over what length of time those characters were changing). In this case, the number of characters changing on a given branch is the amount of evolution along that branch, and the number of changes divided by the time duration of the branch is the rate of evolution of that branch. Amounts and rates can be measured across the phylogeny and binned according to time or clade, giving information on whether certain time intervals or groups of organisms exhibited more or less evolution than others and underwent faster or slower rates of change than others. Such calculations have been done infrequently, but useful primers and case studies have been presented by Wagner (1997) and Ruta et al. (2006). Similar studies, using continuous morphometric data instead of discrete characters, are more common in the literature (e.g. Garland 1992; Collar et al. 2005; O'Meara et al. 2006; Sidlauskas 2007; Pinto et al. 2008; Adams et al. 2009; Cooper \& Purvis 2009).

Triassic-Early Jurassic archosaurs are one of the few groups that have been subjected to studies of evolutionary amount and rate. Brusatte et al. (2008a) used the same large database of morphological characters employed in their disparity analysis, and optimised these features onto a single resolved cladogram generated during a preliminary run of the Brusatte et al. (2010a) phylogeny analysis. They found that, for archosaurs as a whole, the raw amount of character change per branch was static across the Triassic. However, when time entered into the equation, rates of change were significantly highest in the Anisian, the earliest sampled time bin in the analysis, with a general decrease throughout the remainder of the Triassic. Crurotarsans and dinosaurs had indistinguishable amounts and rates of change during the Late Triassic as a whole, as well as during the Norian. During the Carnian crurotarsan and dinosaur amounts were statistically indistinguishable, but dinosaurs did have a significantly higher rate of change per branch than crurotarsans. These general patterns were also found when strict sister taxa (Crurotarsi and Avemetatarsalia) were compared. Analysis of amount and rate of change has yet to be extended into the Early Jurassic, but this will be the subject of future study.
These results have several implications. First, there is once again no evidence that dinosaurs were outcompeting crurotarsans by virtue of higher amounts and rates of evolution, as these measures are essentially identical for the two groups during the Late Triassic. In other words, crurotarsans were keeping pace with the amount and rate of morphological change exhibited by dinosaurs. Secondly, the amount of change per branch was largely constant within archosaurs across the Triassic, indicating that no time period witnessed a great surge of evolutionary novelties, at least in terms of raw numbers. With that being said, however, the rates of character change differed dramatically over time. Rates were highest early in archosaur history and decreased thereafter, which reflects a grand burst of early character evolution that dramatically slowed down over time. Finally, the decreasing rates across the Triassic show the opposite trend to disparity, which increases over time, resulting in a prime empirical example of how rates and disparity may be discordant (see Foote (1997) and Brusatte et al. (2011) for additional discussion of this issue).

Of course, all studies of evolutionary amount and rate rise or fall on the phylogeny that is being used, as well as the absolute ages of the branches (Donoghue \& Ackerly 1996; Wagner 1997). With this in mind, Brusatte et al. (2010c) briefly presented a revised morphological rates analysis, using the published topology of Brusatte et al. (2010a), and found results indistinguishable from those reported by Brusatte et al. (2008a), who utilised a slightly different phylogeny (see above). Even more importantly, Nesbitt (2009a, b) has found a similar pattern of high rates early in archosaur history, but using a different phylogenetic tree and a different database of characters. As these results have only been presented briefly, they will not be discussed further. On the subject of taxon ages, although Brusatte et al. (2008a) used point occurrence ages of the terminal taxa to calibrate branch durations (see Ruta et al. 2006 for more details), congruent results are recovered by unpublished sensitivity analyses that randomise the ages of the terminals to numerous point occurrences within their finest stratigraphic resolution (SLB, GTL \& SCW, unpublished data, briefly presented by Brusatte et al. (2010c); see Pol \& Norell 2006 for general details). Therefore, the overarching pattern of high early rates and a subsequent slowdown appears to be insensitive to phylogenetic topology, absolute branch age durations, and the exact number and type of morphological characters considered.

\section{Archosaur faunal abundance}

In many ways, diversity, disparity and rates of character change are abstract concepts. One measure that is easy to visualise is absolute faunal abundance, or the percentage of individuals or biomass belonging to a species or group within a single ecosystem or region. Absolute numerical abundance is important to consider alongside the aforementioned macroevolutionary metrics, as it is a distinct metric that can quantify the ecological dominance of a group, or lack thereof. For instance, a certain group may include numerous species with widely divergent morphology (high diversity and disparity), but may be exceptionally rare in many ecosystems. On the contrary, one or two taxa with the same general body plan may be remarkably abundant. Unfortunately, measuring absolute abundance in fossil assemblages is difficult due to biases in the fossil record-after all, it is rare for entire ecosystems, especially those including archosaurs, to be preserved-and the high cost in time and resources needed to undertake rigorous faunal censuses. 
Fortunately, Triassic-Early Jurassic vertebrates have been the subject of one of the most comprehensive faunal abundance studies in the literature. Benton (1983) compiled abundance information for archosaurs and a wealth of other terrestrial vertebrates from several localities around the world. Although by now over two decades old, this study remains relevant and we see no reason to doubt the most important general patterns. First, Benton (1983) found that archosaurs were rare in the Middle Triassic, but their abundance spiked in the Carnian. During the Carnian and Norian archosaurs were among the most abundant vertebrates in terrestrial ecosystems, but their abundance varied by latitude and climate zone, and in some cases non-archosaur clades such as rhynchosaurs, dicynodonts, and temnospondyls were more plentiful than archosaurs. However, by the Early Jurassic archosaurs (especially dinosaurs) were the most abundant large terrestrial vertebrates in ecosystems worldwide. Benton (1983) also found that dinosaurs were rare early in their history, in what is now considered the Carnian, but their abundance dramatically increased during the Norian. However, crurotarsans were more abundant than dinosaurs in many Late Triassic ecosystems, and the relative abundances of these two clades varied by location. By the Early Jurassic, however, crurotarsans were rare components of faunas and dinosaurs had become the pre-eminent terrestrial vertebrates globally.

\section{The archosaur radiation: discussion and synthesis}

The radiation of archosaurs during the Triassic and Early Jurassic, long a subject of fascination and a hotbed of speculation, can be understood more objectively by concentrating on the many patterns outlined in this review. Untangling the patterns of lineage origination, diversity, disparity, rates of morphological evolution and faunal abundance unmasks the archosaur radiation as a more complex, drawn-out affair than usually considered. Different macroevolutionary measures, such as diversity and disparity, are not always concordant with each other, and must be considered in unison to understand the major characteristics of the archosaur radiation. With a firm grasp of these patterns, it is reasonable to discuss processes - in this case, reasons why archosaurs radiated and evolved in a certain manner.

\subsection{Trends and processes in all archosaurs}

The major archosaur lineages were established early in the Triassic, certainly by the Anisian and likely much earlier. Rates of morphological character changes were also significantly highest early in archosaur history, and decreased throughout the remainder of the Triassic. However, archosaur diversity, disparity, and faunal abundance remained low throughout the Middle Triassic but increased substantially during the Late Triassic. The main jump in archosaur diversity was between the Carnian and Norian, whereas the significant leaps in disparity and faunal abundance occurred earlier, between the Ladinian and Carnian. Patterns in diversity, disparity, and rate are shown together in Figure 7, which illustrates how these measures are discordant with each other. Figure 8 depicts a general timeline of early archosaur evolution, illustrating the sequence of important events in Triassic-Early Jurassic archosaur history.

What may these patterns reveal about the processes that drove the early evolution of archosaurs? Rates of change peaked long before diversity, disparity and abundance, and high rates are coincident with the lineage splitting events that defined the fundamental archosaur subgroups. This pattern

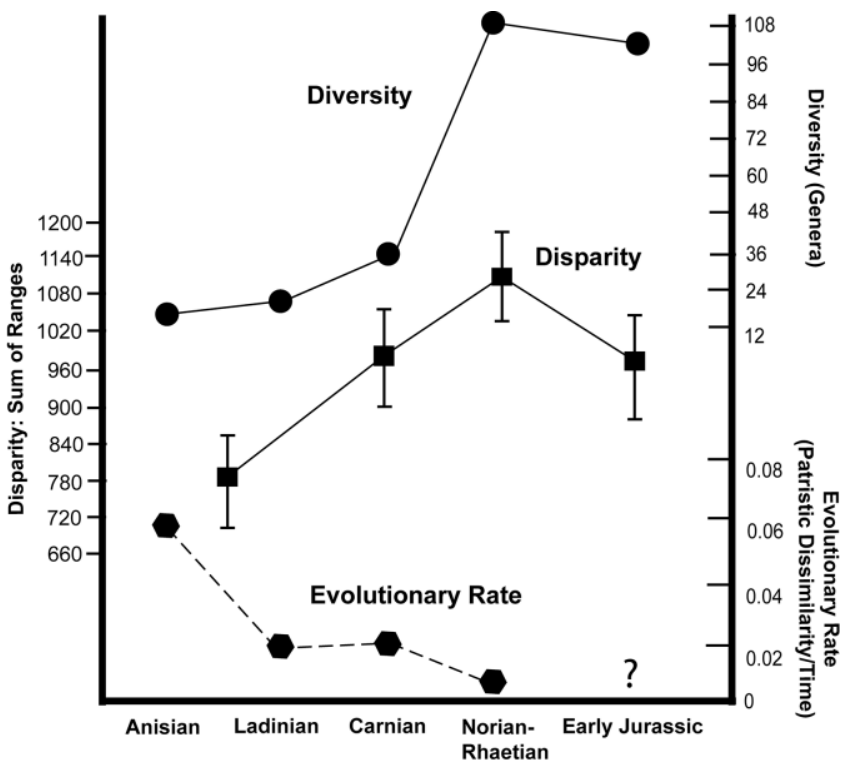

Figure 7 Plots of archosaur diversity (counts of genera, phylogenetically corrected), disparity (sum of ranges), and morphological rates (patristic dissimilarity per branch/time) across the Triassic and Early Jurassic, from Brusatte et al. (2008a, b). Anisian and Ladinian taxa are binned together in the disparity measure to standardise sample size between bins, but individual disparity measures for each stage are reported in Brusatte et al. (2008a). Similarly, two large bins are used to simplify the plot of diversity counts (Norian+Rhaetian; Early Jurassic), although individual measures for each stage are reported in Figure 2. Error bars on disparity values represent $95 \%$ bootstrap confidence intervals, and non-overlapping error bars indicate a significant difference between two time-bin comparisons. Question mark indicates uncertain rate measure for Early Jurassic archosaurs, which is currently under study by the authors. Two important patterns are shown: the major increase in archosaur disparity (Carnian) occurred before the main increase in diversity (Norian), and archosaur morphological rates were highest early in the Triassic, before the disparity and diversity spikes.

corresponds to one predicted for a rapid radiation, in which a burst of character change and differentiation into principal lineages occurs as a clade is presented with a novel evolutionary opportunity, usually either the invasion of new ecospace or the evolution of key innovations (e.g. Valentine 1980; Schluter 2000; Gould 2002; Gavrilets \& Losos 2009). Whether the earliest phase of the archosaur radiation was an adaptive radiation is unclear, as this is difficult to test in long-extinct organisms (Gavrilets \& Losos 2009). However, as archosaur fossils are increasingly being found earlier in time, interpreting the earliest phase of the archosaur radiation as an adaptive response to open ecospace after the Permo-Triassic extinction is becoming more appealing (see Sahney \& Benton 2008; Kubo \& Benton 2009; Nesbitt et al. 2011).

Another interesting pattern is that trends in disparity are discordant with both morphological rates and diversity. A decoupling of diversity and disparity is seen in most fossil groups (see review in Erwin 2007) and is actually expected under many models of morphological evolution (e.g. Foote 1993, 1997). Archosaur disparity and diversity both peaked in the Norian, but the significant increase in disparity was between the Ladinian and Carnian, whereas the major diversity spike occurred between the Carnian and Norian. Therefore, it is reasonable to consider disparity as peaking prior to diversity, a pattern that is found in the majority of empirical studies on fossil taxa (e.g. Foote 1993, 1997; Erwin 2007). The interpretation here differs slightly from that presented by Brusatte et al. (2008a), who, without measures of diversity for context, interpreted the general rise in archosaur disparity across the Triassic as signs of a late peak. The interpretation 


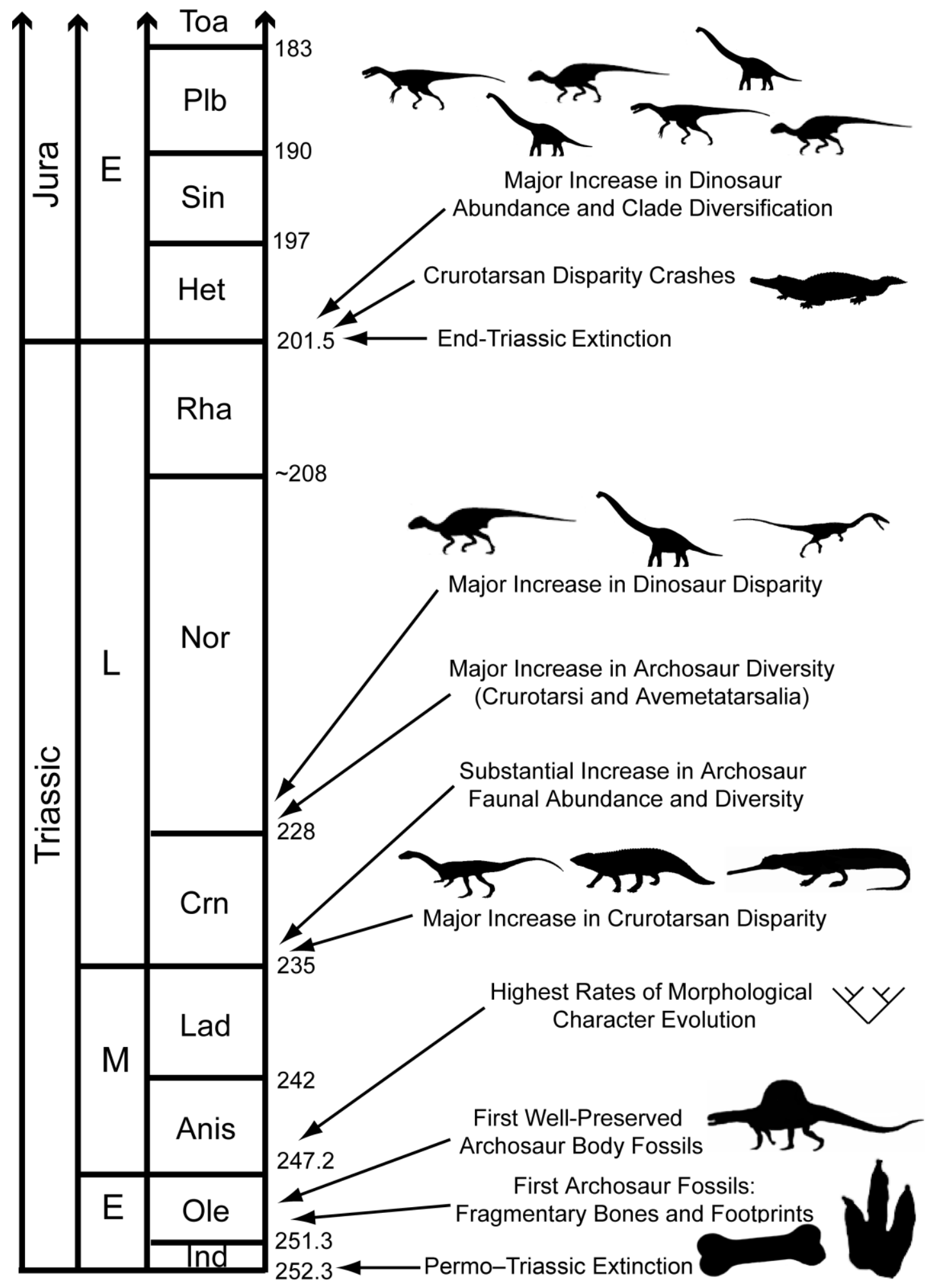

Figure 8 A generalised timeline of important events in Triassic-Early Jurassic archosaur evolution. Timescale, with numbers denoting millions of years before present, based on that of Walker \& Geissman (2009), with modification to include a longer Rhaetian (Muttoni et al. 2010) and other modifications to the Early Triassic outlined by Mundil et al. (2010). Silhouettes modified from Nesbitt (2005), Nesbitt \& Norell (2006) and novel reconstructions created by Frank Ippolito of the AMNH. Abbreviations: Ind=Induan; Ole=Olenekian; Anis=Anisian; Lad=Ladinian; Crn=Carnian; Nor=Norian; Rha=Rhaetian; Het=Hettangian; Sin=Sinemurian; $\mathrm{Plb}=$ Pliensbachian; Toa $=$ Toarcian .

favoured here corresponds to a model of evolution in which fundamental lineages and major body plans are established before a clade settles into a 'modification' phase, characterised by minor variants on the primary morphotypes and speciation within major lineages (e.g., Foote 1993, 1996, 1997). In concert with this, the discrepancy between disparity and rates indicates that the initial burst of character evolution early in archosaur history did not immediately translate into a wide variety of morphology, but only over a longer time period did disparity accumulate in concert with the steady change of anatomical characters. In other words, rates peaked first, then disparity, and finally diversity. 
One clear pattern is the profound difference between Late Triassic and Early Jurassic measures of diversity, disparity and abundance. Disparity substantially decreased across this interval, and crurotarsan disparity in particular endured a statistically significant crash. Diversity, including that of both crurotarsans and avemetatarsalians, was substantially higher in the Norian than during the Rhaetian and throughout the Early Jurassic. Archosaur abundance, likewise, only occasionally eclipsed that of other clades during the Late Triassic, whereas during the Early Jurassic archosaurs were the predominant terrestrial vertebrates globally. Taken together, these patterns indicate that the end-Triassic extinction event had a great effect on early archosaur evolution. The timing, duration, magnitude and causes of this extinction have been heavily debated (see Tanner et al. 2004 and references therein), largely because patterns of Triassic vertebrate faunal change are difficult to assess owing to poor age control and imprecise correlations on a global scale. Recent work, however, strongly points to the onset of Central Atlantic Magmatic Province (CAMP) volcanism as the main driver of this extinction (Deenen et al. 2010; Schoene et al. 2010; Whiteside et al. 2010). Regardless, at the most reductionist level it is apparent that archosaurs were hit hard by whatever happened during this extinction event, no matter its duration or causes. Archosaur diversity, for instance, does not even approach Norian levels during the Early Jurassic (Fig. 3A), despite a better sampled rock record (Barrett et al. 2009).

\subsection{The dinosaur radiation}

Detailed discussion of the dinosaur radiation has been avoided, as this has been covered extensively in recent reviews by Langer et al. (2010) and Brusatte et al. (2010b). However, several patterns discussed here have major implications for the tempo and mode of the dinosaur radiation, and these bear repeating. Crurotarsan archosaurs were more disparate than dinosaurs (and avemetatarsalians as a whole) throughout the Late Triassic, and only after the end-Triassic extinction did dinosaur disparity eclipse that of crurotarsans. Crurotarsans were more diverse than dinosaurs (and avemetatarsalians) during most of the Triassic, the two clades were approximately equally diverse during the Norian, and then crurotarsan diversity crashed relative to that of dinosaurs (and avemetatarsalians) during the Rhaetian and Early Jurassic. Crurotarsans were often more abundant than dinosaurs during the Late Triassic, but by the Early Jurassic dinosaurs were the dominant mid-to-large-sized vertebrates in most terrestrial ecosystems. Both groups, however, underwent similar rates of morphological character change during the Triassic.

Above all, these patterns support two general interpretations. First, there is no sign that dinosaurs (or all avemetatarsalians) were gradually outcompeting or eclipsing crurotarsans during the Late Triassic. Crurotarsans, not dinosaurs, were more disparate, diverse and abundant during this time, and this dynamic was reversed only in the Early Jurassic, after crurotarsans were decimated during the end-Triassic extinction. Both major archosaur clades, the crurotarsans and avemetatarsalians, were successful during the Late Triassic (and it could be argued that the crurotarsans were more so), but the end Triassic extinction, whatever its causes and duration, seemed to change the rules of the game. Secondly, the ascendancy of dinosaurs was a long, drawn-out process that occurred over 50 million years, with decoupled patterns of diversity, disparity and abundance. Indeed, many studies now agree that the rise of dinosaurs was more gradual than previously assumed (e.g. Benton 2004; Irmis et al. 2007; Brusatte et al. 2008a, b, 2010b; Nesbitt et al. 2009; Langer et al. 2010).

\subsection{Summary and conclusion}

The archosaur radiation was a drawn-out event that occurred over a time frame of more than 50 million years (Fig. 8). Archosaurs appear to have radiated rapidly early in the Triassic, as reflected by the establishment of fundamental lineages and high rates of character change. Major increases in disparity and abundance occurred only at the beginning of the Late Triassic, and diversity peaked in the Norian and crashed in the Rhaetian and Early Jurassic. Although archosaurs originated in the Early Triassic (or perhaps earlier), it was not until the Late Triassic that they were abundant across the globe, achieved high species-level diversity, and had evolved into all of the major body plans. Finally, only after the end-Triassic extinction and the decimation of temnospondyls, rhynchosaurs, dicynodonts and other taxa were archosaurs truly the pre-eminent terrestrial vertebrates on a global scale. This emerging view of early archosaur history, pieced together by examining many lines of evidence, provides a cautionary tale against literal reading of the fossil record and clichéd explanations of complex evolutionary events.

\section{Acknowledgements}

We thank the symposium organisers, R. Butler, R. Irmis and M. Langer, for their invitation to participate, R. Irmis and P. Wagner for their helpful reviews, and S. Nesbitt for his thoughtful comments on the draft manuscript. We are especially grateful to our collaborators on various Triassic projects, including R. Butler, J. Desojo, M. Ezcurra, D. Gower, R. Irmis, M. Langer, O. Mateus, S. Nesbitt, G. Niedźwiedzki, M. Norell, and P. Olsen, as well as many others for discussion (R. Benson, M. Coates, I. Corfe, J. Cracraft, P. Donoghue, J. Dzik, J. Flynn, M. Foote, D. Hone, M. LaBarbera, K. Padian, K. Peyer, L. Prendini, N. Smith, P. Sereno, T. Sulej, A. Turner, P. Upchurch, and W. Wheeler). We thank numerous curators for access to specimens in their care (see acknowledgements in Brusatte et al. 2010a). SLB is funded by a Marshall Scholarship for study in the UK (University of Bristol) and an NSF Graduate Research Fellowship (Columbia University), and specimen visits pertinent to this project were funded by the Paleontological Society, Jurassic Foundation, SYNTHESYS, and Bob Savage Memorial Fund (University of Bristol).

\section{References}

Adams, D. C., Berns, C. M., Kozak, K. H. \& Wiens, J. J. 2009. Are rates of species diversification correlated with rates of morphological evolution? Proceedings of the Royal Society B 276, 2729-38.

Bakker, R. T. 1971. Dinosaur physiology and the origin of mammals. Evolution 25, 636-58.

Barrett, P. M., McGowan, A. J. \& Page, V. 2009. Dinosaur diversity and the rock record. Proceedings of the Royal Society B 276, 2667-74.

Bennett, S. C. 1996. The phylogenetic position of the Pterosauria within the Archosauromorpha. Zoological Journal of the Linnean Society 118, 261-308.

Benson, R. B. J., Butler, R. J., Lindgren, J. \& Smith, A. S. 2010. Mesozoic marine tetrapod diversity: mass extinctions and temporal heterogeneity in geological megabiases affecting vertebrates. Proceedings of the Royal Society B 277, 829-34.

Benton, M. J. 1983. Dinosaur success in the Triassic: a noncompetitive ecological model. Quarterly Review of Biology 58, 29-55.

Benton, M. J. 1986a. More than one event in the Late Triassic mass extinction. Nature 321, 857-61.

Benton, M. J. 1986b. The Late Triassic tetrapod extinction events. In Padian, K. (ed.) The Beginning of the Age of Dinosaurs: Faunal Chance across the Triassic-Jurassic Boundary, 303-20. Cambridge, UK: Cambridge University Press. 
Benton, M. J. 1994. Late Triassic to Middle Jurassic extinctions among terrestrial tetrapods: testing the pattern. In Fraser, N. C. \& Sues, H.-D. (eds) In the Shadow of the Dinosaurs: Early Mesozoic Tetrapods, 366-97. Cambridge, UK: Cambridge University Press.

Benton, M. J. 1988. The origins of the dinosaurs. Modern Geology 13, $41-56$.

Benton, M. J. 1999. Scleromochlus taylori and the origin of dinosaurs and pterosaurs. Philosophical Transactions of the Royal Society B 354, $1423-46$.

Benton, M. J. 2004. Origin and relationships of Dinosauria. In Weishampel, D. B., Dodson, P. \& Osmólska, H. (eds) The Dinosauria (2nd edn), 7-24. Berkeley: University of California Press.

Benton, M. J. 2005. Vertebrate Palaeontology (3rd edn). Oxford: Blackwell.

Benton, M. J. 2009. The Red Queen and the Court Jester: species diversity and the role of biotic and abiotic factors through time. Science 323, 728-32.

Benton, M. J., Tverdokhlebov, V. P. \& Surkov, M. V. 2004. Ecosystem remodelling among vertebrates at the Permian-Triassic boundary in Russia. Nature 432, 97-100.

Benton, M. J. \& Clark, J. M. 1988. Archosaur phylogeny and the relationships of the Crocodylia. In Benton, M. J. (ed.) The Phylogeny and Classification of the Tetrapods. Systematics Association Special Volume 35A, 295-338.

Benton, M. J. \& Donoghue, P. C. J. 2007. Paleontological evidence to date the tree of life. Molecular Biology and Evolution 24, 26-53.

Benton, M. J. \& Walker, A. D. 2002. Erpetosuchus, a crocodilelike basal archosaur from the Late Triassic of Elgin, Scotland. Zoological Journal of the Linnean Society 136, 25-47.

Brusatte, S. L. 2007. The higher-level phylogeny of Archosauria (Tetrapoda: Diapsida). Unpublished MSc Thesis, Department of Earth Sciences, University of Bristol, UK. 175 pp.

Brusatte, S. L., Benton, M. J., Ruta, M. \& Lloyd, G. T. 2008 a. Superiority, competition, and opportunism in the evolutionary radiation of dinosaurs. Science 321, 1485-88.

Brusatte, S. L., Benton, M. J., Ruta, M. \& Lloyd, G. T. 2008b. The first $50 \mathrm{Myr}$ of dinosaur evolution: macroevolutionary pattern and morphological disparity. Biology Letters 4, 733-36.

Brusatte, S. L., Butler, R. J., Sulej, T. \& Niedźwiedzki, G. 2009. The taxonomy and anatomy of rauisuchian archosaurs from the Late Triassic of Germany and Poland. Acta Palaeontologica Polonica 54, 221-30.

Brusatte, S. L., Benton, M. J., Desojo, J. B. \& Langer, M. C. 2010a. The higher-level phylogeny of Archosauria (Tetrapoda: Diapsida). Journal of Systematic Palaeontology 8, 3-47.

Brusatte, S. L., Nesbitt, S. J., Irmis, R. B., Butler, R. J., Benton, M. J. \& Norell, M. A. 2010b. The origin and early radiation of dinosaurs. Earth-Science Reviews 101, 68-100.

Brusatte, S. L., Lloyd, G. T. \& Wang, S. C. 2010c. Morphological evolution in Triassic archosaurs: rates of character change during an exemplary evolutionary radiation. In Programme and Abstracts of the Third International Palaeontological Congress, London, 2010, 104.

Brusatte, S. L., Montanari, S., Yi, H.-Y. \& Norell, M. A. 2011. Phylogenetic corrections for morphological disparity analysis: new methodology and case studies. Paleobiology 37, 1-22.

Butler, R. J., Smith, R. M. H. \& Norman, D. B. 2007. A primitive ornithischian dinosaur from the Late Triassic of South Africa, and the early evolution and diversification of Ornithischia. Proceedings of the Royal Society B 274, 2041-46.

Butler, R. J. \& Goswami, A. 2008. Body size evolution in Mesozoic birds: little evidence for Cope's rule. Journal of Evolutionary Biology 21, 1673-82.

Chan, K. M. A. \& Moore, B. R. 2002. Whole-tree methods for detecting differential diversification rates. Systematic Biology 51, 855-65.

Chan, K. M. A. \& Moore, B. R. 2005. SymmeTREE: whole-tree analysis of differential diversification rates. Bioinformatics 21, 1709-10.

Charig, A. J. 1980. Differentiation of lineages among Mesozoic tetrapods. Mémoires de la Société géologique de France 139, 207-10.

Charig, A. J. 1984. Competition between therapsids and archosaurs during the Triassic Period: a review and synthesis of current theories. Symposium of the Zoological Society of London 52, 597-628.

Ciampaglio, C. N., Kemp, M. \& McShea, D. W. 2001. Detecting changes in morphospace occupation patterns in the fossil record: characterization and analysis of measures of disparity. Paleobiology 27, 695-715.
Clark, J. M., Xu, X, Forster, C. A. \& Wang, Y. 2004. A Middle Jurassic 'sphenosuchian' from China and the origin of the crocodylian skull. Nature 430, 1021-24.

Collar, D. C., Near, T. J. \& Wainwright, P. C. 2005. Comparative analysis of morphological diversity: does disparity accumulate at the same rate in two lineages of centrarchid fishes? Evolution 59, 1783-94.

Cooper, N. \& Purvis, A. 2009. What factors shape rates of phenotypic evolution? A comparative study of cranial morphology of four mammalian clades. Journal of Evolutionary Biology 22, 1024-35.

Cope, E. D. 1869. Synopsis of the extinct Batrachia, Reptilia and Aves of North America. Transactions of the American Philosophical Society 14, 1-252.

Cox, C. B. 1967. Changes in terrestrial vertebrate faunas during the Mesozoic. In Harland, W. B., Holland, C. H., House, M. R., Hughes, N. F., Reynolds, A. B., Rudwick, M. J. S., Satterthwaite, G. E., Tarlo, L. B. H. \& Willey, E. C. (eds) The Fossil Record, 77-89. London: The Geological Society.

Crompton, A. W. 1968. The enigma of the evolution of mammals. Optima 18, 137-51.

Deenen, M. H. L., Ruhl, M., Bonis, N. R., Krijgsman, W., Kuerschner, W. M., Reitsma, M. \& van Bergen, M. J. 2010. A new chronology for the end-Triassic mass extinction. Earth and Planetary Science Letters 291, 113-25.

Diedrich, C. 2008. Millions of reptile tracks - Early to Middle Triassic carbonate tidal flat migration bridges of Central Europe - reptile immigration into the Germanic Basin. Palaeogeography, Palaeoclimatology, Palaeoecology 259, 410-23.

Donoghue, M. J. \& Ackerly, D. D. 1996. Phylogenetic uncertainties and sensitivity analyses in comparative biology. Philosophical Transactions of the Royal Society B 352, 1241-49.

Dzik, J. 2003. A beaked herbivorous archosaur with dinosaur affinities from the early Late Triassic of Poland. Journal of Vertebrate Paleontology 23, 556-74.

Dzik, J., Sulej, T. \& Niedźwiedzki, G. 2008. A dicynodont-theropod association in the latest Triassic of Poland. Acta Palaeontologica Polonica 53, 733-38.

Erwin, D. H. 2007. Disparity: morphological pattern and developmental context. Palaeontology 50, 57-73.

Ezcurra, M. D. 2010. Biogeography of Triassic tetrapods: evidence for provincialism and driven sympatric cladogenesis in the early evolution of modern tetrapod lineages. Proceedings of the Royal Society B 277, 2547-52.

Fara, E. 2004. Estimating minimum global species diversity for groups with a poor fossil record: a case study of Late Jurassic-Eocene lissamphibians. Palaeogeography, Palaeoclimatology, Palaeoecology 207, 59-82.

Foote, M. 1993. Discordance and concordance between morphological and taxonomic diversity. Paleobiology 19, 185-204.

Foote, M. 1996. Models of morphological diversification. In Jablonski, D., Erwin, D. H. \& Lipps, J. H. (eds) Evolutionary Paleobiology, 62-86. Chicago, Illinois: University of Chicago Press.

Foote, M. 1997. The evolution of morphological diversity. Annual Review of Ecology and Systematics 28, 129-52.

Foote, M. 2001. Inferring temporal patterns of preservation, origination, and extinction from taxonomic survivorship analysis. Paleobiology 27, 602-30.

Fröbisch, J. 2008. Global taxonomic diversity of anomodonts (Tetrapoda, Therapsida) and the terrestrial rock record across the Permian-Triassic boundary. PLoS One 3, e3733.

Fuglewicz, R., Ptaszyński, T. \& Rdzanek, K. 1990. Lower Triassic footprints from the Swietokrzyskie (Holy Cross) Mountains, Poland. Acta Palaeontologica Polonica 35, 109-64.

Furin, S., Preto, N., Rigo, M., Roghi, G., Gianolla, P., Crowley, J. L. \& Bowring, S. A. 2006. High-precision U-Pb zircon age from the Triassic of Italy: Implications for the Triassic time scale and the Carnian origin of calcareous nannoplankton and dinosaurs. Geology 34, 1009-12.

Garland, T. G. 1992. Rate tests for phenotypic evolution using phylogenetically independent contrasts. The American Naturalist 140, 509-19.

Gauthier, J. A. 1986. Saurischian monophyly and the origin of birds. Memoirs of the California Academy of Sciences 8, 1-55.

Gavrilets, S. \& Losos, J. B. 2009. Adaptive radiation: contrasting theory with data. Science 323, 732-37.

Gebauer, E. V. I. 2004. Neubeschreibung von Stagonosuchus nyassicus v. Huene, 1938 (Thecodontia, Rauisuchia) aus der MandaFormation (Mittlere Trias) von Südwest-Tansania. Neues Jahrbuch für Geologie und Paläontologie, Abhandlungen 231, 1-35. 
Gould, S. J. 1991. The disparity of the Burgess Shale arthropod fauna and the limits of cladistic analysis: why we must strive to quantify morphospace. Paleobiology 17, 411-23.

Gould, S. J. 2002. The Structure of Evolutionary Theory. Cambridge, Massachusetts: Harvard University Press.

Gower, D. J. 1999. The cranial and mandibular osteology of a new rauisuchian archosaur from the Middle Triassic of southern Germany. Stuttgarter Beiträge zur Naturkunde (Serie B) $\mathbf{2 8 0}$, $1-49$.

Gower, D. J. 2002. Braincase evolution in suchian archosaurs (Reptilia: Diapsida): evidence from the rauisuchian Batrachotomus kupferzellensis. Zoological Journal of the Linnean Society 136, 49-76.

Gradstein, F., Ogg, J. \& Smith, A. G. 2004. A Geologic Time Scale 2004. Cambridge, UK: Cambridge University Press.

Halstead, L. B. 1975. The Evolution and Ecology of the Dinosaurs. London: Peter Lowe.

Hungerbühler, A. 2002. The Late Triassic phytosaur Mystriosuchus westphali, with a revision of the genus. Palaeontology 45, 377-418.

Haubold, H. 1999. Tracks of the Dinosauromorpha from the Early Triassic. Zentralblatt fur Geologie und Paläontologie Teil I 1998, $783-95$.

Irmis, R. B. 2011. Evaluating hypotheses for the early diversification of dinosaurs. Earth \& Environmental Science Transactions of the Royal Society of Edinburgh 101 (for 2010), 397-426.

Irmis, R. B., Nesbitt, S. J., Padian, K., Smith, N. D., Turner, A. H., Woody, D. \& Downs, A. 2007. A Late Triassic dinosauromorph assemblage from New Mexico and the rise of dinosaurs. Science 317, 358-61.

Irmis, R. \& Mundil, R. 2008. New age constraints from the Chinle Formation revise global comparisons of Late Triassic vertebrate assemblages. Journal of Vertebrate Paleontology 28 (3), 95A.

Jalil, N.-E. \& Peyer, K. 2007. A new rauisuchian (Archosauria, Suchia) from the Upper Triassic of the Argana Basin, Morocco. Palaeontology 50, 417-30.

Jones, K. E., Bininda-Emonds, O. R. P. \& Gittleman, J. L. 2005. Bats, clocks, and rocks: diversification patterns in Chrioptera. Evolution 59, 2243-55.

Juul, L. 1994. The phylogeny of basal archosaurs. Palaeontologia Africana 31, 1-38.

Kellner, A. W. A. 2003. Pterosaur phylogeny and comments on the evolutionary history of the group. Geological Society, London, Special Publications 217, 105-37.

Klein, H. \& Haubold, H. 2007. Archosaur footprints-potential for biochronology of Triassic continental sequences. In Lucas, S. G. \& Spielmann, J. A. (eds) The Global Triassic. New Mexico Museum of Natural History and Science Bulletin 41, 120-30. Albuquerque: New Mexico Museum of Natural History and Science.

Kubo, T. \& Benton, M. J. 2009. Tetrapod postural shift estimated from Permian and Triassic trackways. Palaeontology 52, 1029-37.

Langer, M. C., Ezcurra, M. D., Bittencourt, J. S. \& Novas, F. E. 2010. The origin and early evolution of dinosaurs. Biological Reviews 85, 55-110.

Langer, M. C. \& Benton, M. J. 2006. Early dinosaurs: a phylogenetic study. Journal of Systematic Palaeontology 4, 309-58.

Li, C., Wu, X.-C., Cheng, Y.-N., Sato, T. \& Wang, L. 2006. An unusual archosaurian from the marine Triassic of China. Naturwissenschaften 93, 200-06.

Lloyd, G. T., Davis, K. E., Pisani, D., Tarver, J. E., Ruta, M., Sakamoto, M., Hone, D. W. E., Jennings, R. \& Benton, M. J. 2008. Dinosaurs and the Cretaceous Terrestrial Revolution. Proceedings of the Royal Society B 275, 2483-90.

Melchor, R. N. \& Valais, S. D. 2006. A review of Triassic tetrapod track assemblages from Argentina. Palaeontology 49, 355-79.

Müller, J. \& Reisz, R. R. 2005. Four well-constrained calibration points from the vertebrate fossil record for molecular clock estimates. BioEssays 27, 1069-75.

Mundil, R., Pálfy, J., Renne, P. R. \& Brack, P. 2010. The Triassic timescale: new constraints and a review of geochronological data. Geological Society, London, Special Publications 334, 41-60.

Muttoni, G., Kent, D. V., Olsen, P. E., Di Stefano, P., Lowrie, W., Bernasconi, S. M. \& Hernandez, F. M. 2004. Tethyan magnetostratigraphy from Pizzo Mondello (Sicily) and correlation to the Late Triassic Newark astrochronological polarity time scale. Geological Society of America Bulletin 116, 1043-58.

Muttoni, G., Kent, D. V., Jadoul, F., Olsen, P. E., Rigo, M., Teresa, M. \& Nicora, A. 2010. Rhaetian magneto-biostratigraphy from the Southern Alps (Italy): constraints on Triassic chronology. Palaeogeography, Palaeoclimatology, Palaeoecology 285, 1-16.
Nee, S. 2006. Birth-death models in macroevolution. Annual Review of Ecology, Evolution, and Systematics 37, 1-17.

Nesbitt, S. J. 2003. Arizonasaurus and its implications for archosaur divergence. Proceedings of the Royal Society B 270, S234-37.

Nesbitt, S. J. 2005. The osteology of the pseudosuchian Arizonasaurus babbitti. Historical Biology 17, 19-47.

Nesbitt, S. J. 2007. The anatomy of Effigia okeeffeae (Archosauria, Suchia), theropod-Like convergence, and the distribution of related taxa. Bulletin of the American Museum of Natural History 302, 1-84.

Nesbitt, S. J. 2009a. The early evolution of archosaurs: Relationships and the origin of major clades. Unpublished PhD Dissertation. Earth and Environmental Sciences, Columbia University, New York, $675 \mathrm{pp}$

Nesbitt, S. J. 2009b. The antiquity of Archosauria and the origin of Late Triassic archosaur assemblages. Journal of Vertebrate Paleontology 29 (3), 155A.

Nesbitt, S. J., Irmis, R. B. \& Parker, W. G. 2007. A critical reevaluation of the Late Triassic dinosaur taxa of North America. Journal of Systematic Palaeontology 5, 209-43.

Nesbitt, S. J., Smith, N. D., Irmis, R. B., Turner, A. H., Downs, A. \& Norell, M. A. 2009. A complete skeleton of a Late Triassic saurischian and the early evolution of dinosaurs. Science 326, $1530-33$.

Nesbitt, S. J., Sidor, C. A., Irmis, R. B., Angielczyk, K. D., Smith, R. M. H. \& Tsuji, L. A. 2010. Ecologically distinct dinosaurian sister group shows early diversification of Ornithodira. Nature 464, 95-98.

Nesbitt, S. J., Liu, J. \& Li, C. 2011. A sail-backed suchian from the Heshanggou Formation (Early Triassic: Olenekian) of China. Earth \& Environmental Science Transactions of the Royal Society of Edinburgh 101 (for 2010), 271-84.

Nesbitt, S. J. \& Norell, M. A. 2006. Extreme convergence in the body plans of an early suchian (Archosauria) and ornithomimid dinosaurs (Theropoda). Proceedings of the Royal Society B 273, 1045-48.

Niedźwiedzki, G. \& Ptaszyński, T. 2007. Large Chirotheriidae tracks in the Early Triassic of Wióry, Holy Cross Mountains, Poland. Acta Geologica Polonica 57, 325-42.

Norell, M. A. 1992. Taxic origin and temporal diversity: the effect of phylogeny. In Novacek, M. J. \& Wheeler, Q. D. (eds) Extinction and Phylogeny, 89-118. New York: Columbia University Press.

O'Meara, B. C., Ané, C., Sanderson, M. J. \& Wainwright, P. C. 2006. Testing for different rates of continuous trait evolution using likelihood. Evolution 60, 922-33.

Parker, W. G. 2007. Reassessment of the aetosaur 'Desmatosuchus' chamaensis with a reanalysis of the phylogeny of the Aetosauria (Archosauria: Pseudosuchia). Journal of Systematic Palaeontology 5, 41-68.

Parker, W. G., Irmis, R. B., Nesbitt, S. J., Martz, J. W. \& Browne, L. S. 2005. The Late Triassic pseudosuchian Revueltosaurus callenderi and its implications for the diversity of early ornithischian dinosaurs. Proceedings of the Royal Society B 272, 963-69.

Parrish, J. M. 1993. Phylogeny of the Crocodylotarsi, with reference to archosaurian and crurotarsan monophyly. Journal of Vertebrate Paleontology 13, 287-308.

Peters, S. E. \& Foote, M. 2001. Biodiversity in the Phanerozoic: a reinterpretation. Paleobiology 27, 583-601.

Pinto, G., Mahler, D. L., Harmon, L. J. \& Losos, J. B. 2008. Testing the island effect in adaptive radiation: rates and patterns of morphological diversification in Caribbean and mainland Anolis lizards. Proceedings of the Royal Society B 275, 2749-57.

Pol, D. \& Norell, M. A. 2006. Uncertainty in the age of fossils and the stratigraphic fit to phylogenies. Systematic Biology 55, 512-21.

Ptaszyński, T. 2000. Lower Triassic vertebrate footprints from Wióry, Holy Cross Mountains, Poland. Acta Paleontologica Polonica 45, $151-94$.

Purvis, A. 2008. Phylogenetic approaches to the study of extinction. Annual Review of Ecology, Evolution, and Systematics 39, 301-19.

Ricklefs, R. E. 2006. Time, species, and the generation of trait variance in clades. Systematic Biology 55, 151-59.

Ricklefs, R. E. 2007. Estimating diversification rates from phylogenetic information. Trends in Ecology and Evolution 22, 601-10.

Robinson, P. L. 1971. A problem of faunal replacement on PermoTriassic continents. Palaeontology 14, 131-53.

Romer, A. S. 1956. Vertebrate Paleontology. Chicago, Illinois: University of Chicago Press.

Ruta, M., Wagner, P. J. \& Coates, M. I. 2006. Evolutionary patterns in early tetrapods. I. Rapid initial diversification followed by decrease in rates of character change. Proceedings of the Royal Society B 273, 2107-11. 
Ruta, M., Pisani, D., Lloyd, G. T. \& Benton, M. J. 2007. A supertree of Temnospondyli: cladogenetic patterns in the most species-rich group of early tetrapods. Proceedings of the Royal Society B 274, 3087-95.

Sahney, S. \& Benton, M. J. 2008. Recovery from the most profound mass extinction of all time. Proceedings of the Royal Society $B$ 275, 759-65.

Schluter, D. 2000. The Ecology of Adaptive Radiation. Oxford: Oxford University Press.

Schoene, B., Guex, J., Bartolini, A., Schaltegger, U. \& Blackburn, T. J. 2010. Correlating the end-Triassic mass extinction and flood basalt volcanism at the $100 \mathrm{ka}$ level. Geology 38, 387-90.

Sen, K. 2005. A new rauisuchian archosaur from the Middle Triassic of India. Palaeontology 48, 185-96.

Sereno, P. C. 1991. Basal archosaurs: phylogenetic relationships and functional implications. Society of Vertebrate Paleontology Memoir 2, 1-53.

Sereno, P. C. \& Arcucci, A. B. 1990. The monophyly of crurotarsal archosaurs and the origin of bird and crocodile ankle joints. Neues Jahrbuch für Geologie und Paläontologie, Abhandlungen 180, 21-52.

Shubin, N. H. \& Sues, H.-D. 1991. Biogeography of early Mesozoic continental deposits: patterns and implications. Paleobiology 17, 214-30.

Sidlauskas, B. L. 2007. Testing for unequal rates of morphological diversification in the absence of a detailed phylogeny: a case study from characiform fishes. Evolution 61, 299-316.

Sill, W. D. 1974. The anatomy of Saurosuchus galilei and the relationships of the rauisuchid thecodonts. Bulletin of the Museum of Comparative Zoology 146, 317-62.

Smith, A. B. 1988. Patterns of diversification and extinction in early Palaeozoic echinoderms. Palaeontology 31, 799-828.

Smith, A. B. 2001. Large-scale heterogeneity of the fossil record: implications for Phanaerozoic diversity studies. Philosophical Transactions of the Royal Society of London 356, 351-67.

Smith, N. D., Makovicky, P. J., Hammer, W. R. \& Currie, P. J. 2007. Osteology of Cryolophosaurus ellioti (Dinosauria: Theropoda) from the Early Jurassic of Antarctica and implications for early theropod evolution. Zoological Journal of the Linnean Society 151, 377-421.

Tanner, L. H., Lucas, S. G. \& Chapman, M. G. 2004. Assessing the record and causes of Late Triassic extinctions. Earth-Science Reviews 65, 103-39.

Tsuji, L. A. \& Müller, J. 2009. Assembling the history of the Parareptilia: phylogeny, diversification, and a new definition of the clade. Fossil Record 12, 71-81.

Upchurch, P., Barrett, P. M. \& Galton, P. M. 2007. A phylogenetic analysis of basal sauropodomorph relationships: implications for the origin of sauropod dinosaurs. Special Papers in Palaeontology 77, 57-90.

Valentine, J. W. 1980. Determinants of diversity in higher taxonomic categories. Paleobiology 6, 444-50.

Wagner, P. J. 1997. Patterns of morphologic diversification among the Rostroconchia. Paleobiology 23, 115-50.

Walker, J. D. \& Geissman, J. W. 2009. GSA Geologic Time Scale. GSA Today 19, 60-61.

Weinbaum, J. C. \& Hungerbühler, A. 2007. A revision of Poposaurus gracilis (Archosauria: Suchia) based on two new specimens from the Late Triassic of the southwestern USA. Paläontologische Zeitschrift 81, 131-45.

Welles, S. P. 1986. Thoughts on the origin of the Theropoda. In Padian, K. (ed.) The Beginning of the Age of Dinosaurs: Faunal Change across the Triassic-Jurassic Boundary, 31-34. Cambridge, UK: Cambridge University Press.

Whiteside, J. H., Olsen, P. E., Eglinton, T., Brookfield, M. E. \& Sambrotto, R. N. 2010. Compound-specific carbon isotopes from Earth's largest flood basalt province directly link eruptions to the end-Triassic mass extinction. Proceedings of the National Academy of Sciences 107, 6721-25.

Wills, M. A., Briggs, D. E. G. \& Fortey, R. A. 1994. Disparity as an evolutionary index: a comparison of Cambrian and Recent arthropods. Paleobiology 20, 93-131.

Wing, S. L., Hickey, L. J. \& Swisher, C. C. 1993. Implications of an exceptional fossil flora for Late Cretaceous vegetation. Nature 363, 342-44.

MS received 29 December 2009. Accepted for publication 7 October 2010. 